\title{
Resveratrol sensitizes lung cancer cell to TRAIL by p53 independent and suppression of Akt/NF- $\mathrm{kB}$ signaling
}

\author{
Mohammad Rasheduzzaman ${ }^{1}$, Jae-Kyo Jeong ${ }^{1}$, Sang-Youel Park ${ }^{*}$ \\ Biosafety Research Institute, College of Veterinary Medicine, Chonbuk National University, Iksan, Jeonbuk 54596, South Korea
}

\section{A R T I C L E I N F O}

\section{Keywords:}

Resveratrol

TRAIL

Apoptosis

Lung cancer cells

Akt/NF-кB

Cytochrome $c$

\begin{abstract}
A B S T R A C T
Aims: TRAIL is a promising anticancer agent that has the potential to sensitize a wide variety of cancer or transformed cells by inducing apoptosis. However, resistance to TRAIL is a growing concern. Current manuscript aimed to employ combination treatment to investigate resveratrol induced TRAIL sensitization in NSCLC.

Method: A549 and HCC-15 cells were used in an experimental design. Cell viability was determined by morphological image, crystal violet staining and MTT assay. Apoptosis was evaluated by LDH assay, Annexin V and DAPI staining. Autophagy and apoptosis indicator protein were examined by western blotting. TEM and puncta assay was carried out to evaluate the autophagy. MTP and ROS activity was evaluated by JC- 1 and $\mathrm{H}_{2}$ DCFDA staining.

Findings: Resveratrol is a polyphenolic compound capable of activation of tumor suppressor p53 and its proapoptotic modulator PUMA. Herein, we showed the p53-independent apoptosis by decrease the expression of phosphorylated Akt-mediated suppression of NF-kB that is also substantiated with the downregulation of antiapoptotic factors Bcl-2 and Bcl-xl in NSCLC, resulting in an attenuation of TRAIL resistance in combined treatment. Furthermore, apoptosis was induced in TRAIL-resistant lung cancer cells with a co-treatment of resveratrol and TRAIL assessed by the loss of MMP, ROS generations which resulting the translocation of cytochrome $c$ from the mitochondria into the cytosol due to mitochondrial dysfunction. Moreover, autophagy flux was not affected by resveratrol-induced TRAIL-mediated apoptosis in NSCLC.

Significance: Overall, targeting the NF- $\mathrm{BB}$ (p65) pathway via resveratrol attenuates TRAIL resistance and induces TRAIL-mediated apoptosis which could be the effective TRAIL-based cancer therapy regimen.
\end{abstract}

\section{Introduction}

Cancer is a concerning disease and a leading cause of death. There are ongoing basic research studies and clinical trials for the developing of treatment options to ameliorate cancer [1]. Currently, lung adenocarcinoma is one of the leading causes of cancer deaths. Several available anticancer therapy regimens include radiotherapy, surgery, chemotherapeutic drugs or a combination of treatments in patients with advanced progressive tumors that are resistant to monotherapy. Small molecules like tyrosin kinase inhibitors- gefitinib, erlotinib, sorafenib, VEGF Receptor 2 inhibitor-apatinib, PI3K inhibitors, Bcl-2 inhibitors, serine/threonine kinase inhibitor-temsirolimus etc. are popular targeted therapy regimen for the cancer patient. Additionally, combination therapies with potent chemotherapeutic agents can exert potential benefits against cancers such as non-small cell lung adenocarcinoma (NSCLC) [2-4].
Tumor necrosis factor-related apoptosis-inducing ligand (TRAIL) induces apoptosis in cancer or transformed cells but not in normal cells. The death-inducing signaling complex is activated by binding to its death receptors, DR4 and DR5, which then associates with the adaptor molecules FADD and caspase-8, resulting in the TRAIL-mediated activation of caspase- 9 and subsequent activation of caspase- 3 to induce apoptosis [5, 6]. The release of cytochrome $c$ and Smac/DIABLO from the mitochondria modulates caspase- 3 activation and TRAIL via an intrinsic pathway when apoptosis is being induced [7]. Although TRAIL selectively affects cancer or uncontrolled proliferating cells while leaving normal cells unharmed, many cancer cells can become resistant to TRAIL through mechanisms that are not fully understood. Several studies have shown that genetic or epigenetic modification of TRAIL receptors, an increased expression of decoy receptors, or a decreased expression of DR4/DR5 correlates with TRAIL resistance [8, 9]. Furthermore, proteins, such as Bcl-2, Bcl-xl, anti-apoptotic c-FLIP, and pro-

\footnotetext{
* Corresponding author at: College of Veterinary Medicine, Chonbuk National University, Gobongro, Iksan, Jeonbuk 54596, South Korea.

E-mail address: sypark@chonbuk.ac.kr (S.-Y. Park).

1 These authors are equal contribution to this work.
} 
apoptotic protein Bax, and Bak, which is considered an apoptotic regulatory protein, may affect the functions of TRAIL [7, 10, 11]. TRAIL receptor-mediated activation of $\mathrm{NF}-\mathrm{\kappa B}$ (p65) also contributes to the apoptotic resistance of TRAIL in different cancer cells [12, 13]. Overall, studies on TRAIL resistance as well as effective and favorable combination drug therapies have been performed to improve the outcomes of certain cancer treatments [14-16].

Apoptosis is characterized by specific cell morphologies that include cell shrinkage, blebs, nucleus fragmentation, chromatin condensation, and distinct apoptotic body formation [17, 18]. Apoptosis can occur through two major pathways including the extrinsic cell death receptormediated pathway or the mitochondria-mediated pathway via the activation of caspase [19]. The activation of apoptotic pathways plays a major protective role in preventing the spread of cancer. Studies have also shown that numerous anticancer drugs may damage the mitochondria, therefore affecting the mitochondrial membrane potential (MMP), resulting in the release of cytochrome $c$ and subsequent activation of apoptosis via the caspase cascade [20, 21]. Additionally, the p53 transcription factor can induce cell cycle arrest, DNA damage, cellular senescence, and apoptosis in different cancer cell types [22, 23]. p53 independent apoptosis cascade formation also now considerable issue [24, 25]. NF- $\mathrm{KB}$ (p65), a pro-inflammatory transcription factor that is activated by numerous inflammatory agents, tumor promoters, carcinogens, and the tumor microenvironment could also promote tumorigenesis. Proteins regulated by NF- $\mathrm{\kappa B}$ may also contribute to cellular proliferation, apoptosis suppression, angiogenesis, and metastasis, and the suppression of NF- $\mathrm{BB}$ (p65) has been shown to provide effective therapeutic benefits in cancer treatments [26, 27]. NF- $\mathrm{B}$ (p65) regulates anti-apoptotic proteins Bcl-2 and Bcl-xl, both of which localize to the mitochondrial outer membrane where they play a significant role in promoting cell survival and inhibiting pro-apoptotic proteins such as Bax and Bak, which are known to induce apoptosis via permeabilization and the release of cytochrome $c$ [28, 29]. Finally, the Akt cell survival signaling pathway also plays a key role in the regulation of apoptosis via NF-kB (p65) [30, 31].

Autophagy is the homeostatic and adaptive system that results in the lysosomal digestion of cytoplasmic components and organelles [32, 33]. Autophagy begins with the maturation of autophagosomes, double-membrane vesicles that engulf cytoplasmic components, which then fuses with the lysosome, resulting in the subsequent degradation and recycling of its cargo [34, 35]. The formation of autophagosomes is regulated by the Atg12-Atg5-Atg16 complex and microtubule-associated protein light chain 3 (LC3-I)-phospholipid conjugates (LC3-II), both of which could be used as markers for autophagy [36-38]. Furthermore, the autophagy marker p62 is incorporated into autophagosomes by interaction with LC3, which is then degraded during autophagy. Overall, autophagy and apoptotic signaling pathways govern cell survival and cell deaths [39, 40].

Resveratrol (3,5,4'-trihydroxy-trans-stilbene) is a naturally occurring phytochemical that is produced by plants and is mostly found in grape skins, mulberries, raspberries, peanuts, and red wine [41]. Resveratrol has been shown to have diverse biological properties, including anti-inflammatory, antioxidant, antiviral, neuroprotective, antifungal, and anticancer properties [42-45]. Furthermore, resveratrol strongly inhibits the initiation, promotion, and progression of tumors in multiple cancers while the exact molecular mechanisms is unclear. [46-49].

Although resveratrol activates p53 \& its pro-apoptotic modulator PUMA, Here, we demonstrate that p53-independent activation of apoptosis by decrease the expression of phosphorylated Akt-mediated suppression of NF- $\mathrm{KB}$, results in the downregulation of Bcl-2, Bcl-xl and release of cytochrome $c$ due to mitochondrial dysfunction in A549 human lung adenocarcinoma cells, therefore attenuating TRAIL resistance.

\section{Materials and methods}

\subsection{Cell culture}

Cancer cells originating from lung (A549, HCC-15) tumors were obtained from the American Type Culture Collection (Global Bioresource Center, Manassas, VA, USA). P53-containing ( $553^{+/-}$) and p53 knockout $\left(\mathrm{p} 53^{-/-}\right)$HCT116 human colon carcinoma cell lines were provided by Dr. Bert Vogelstein (Johns Hopkins University School of Medicine, Baltimore, MD). Cells were cultured in RPMI-1640 (Gibco BRL, Grand Island, NY, USA) medium supplemented with $10 \%(\mathrm{v} / \mathrm{v})$ fetal bovine serum and antibiotics $(100 \mu \mathrm{g} / \mathrm{ml}$ penicillin-streptomycin). Cells were incubated at $37{ }^{\circ} \mathrm{C}$ in a $5 \% \mathrm{CO}_{2}$ environment.

\subsection{Reagents}

Resveratrol, chloroquine $(20 \mu \mathrm{M})$, and Pifithrin $\alpha$, ZVAD FMK, LY294002 were purchased from Sigma-Aldrich (St. Louis, MO, USA). TRAIL $(100 \mathrm{ng} / \mathrm{ml}$ ) was purchased from Abfrontier (Geumcheon-gu, Seoul, South Korea).

\subsection{Cell viability test}

A549 cells were seeded at a density of $1.0 \times 10^{4}$ cells onto 12 -well plates and incubated at $37^{\circ} \mathrm{C}$ for $24 \mathrm{~h}$. The A549 cells were pretreated with Resveratrol at serial concentrations of $(0,12.5,25,50 \mu \mathrm{M})$ following $12 \mathrm{~h}$ then recombinant TRAIL protein $(100 \mathrm{ng} / \mathrm{ml})$ was added and co-incubated for additional $2.3 \mathrm{~h}$. Additionally, cells were pretreated with pifithrin $\alpha(40 \mu \mathrm{M})$ and chloroquine $(20 \mu \mathrm{M})$ for $1 \mathrm{~h}$, followed by Resveratrol treatment. Cell morphology was assessed by taking photographs under inverted microscope (Nikon, Japan). Cell viability was measured by adding $50 \mu \mathrm{l}$ of $5 \mathrm{mg} / \mathrm{ml}$ methyl-thiazolyltetrazolium (MTT) to each well, and the plates were incubated at $37^{\circ} \mathrm{C}$ for $2 \mathrm{~h}$. Then, $500 \mu \mathrm{l}$ dimethyl sulfoxide was added to each well after removal of the old medium, and absorbance was measured by the spectrophotometer (Bio-Rad, Hercules, CA, USA) at $570 \mathrm{~nm}$. Cells morphological changes were also determined by using the crystal violet staining method. In brief, cells were stained with a staining solution ( $0.5 \%$ crystal violet in 30\% ethanol and 3\% formaldehyde) for $10 \mathrm{~min}$ at room temperature, washed four times with PBS, and dried. Cell viability was expressed as relative dye intensity compared with that of the control. DAPI, or 4',6-diamidino-2-phenylindole staining was carried out by growing the cells in the cover glass then triton-x and PBS washing. Finally stained the cells with DAPI for $10 \mathrm{~min}$ and observed under the fluorescence microscope.

\subsection{Annexin V assay}

Apoptosis was measured by using an annexin V assay kit (Santa Cruz Biotechnology, Santa Cruz, CA, USA) according to the manufacturer's protocol. Annexin $\mathrm{V}$ levels were determined by measuring fluorescence at $488 \mathrm{~nm}$ of excitation and 525/30 emission using a Guava easyCyte HT System (Millipore, Bedford, MA, USA).

\subsection{Lactate dehydrogenase assay}

Cytotoxicity from supernatants assessed by using a lactate dehydrogenase (LDH) cytotoxicity detection kit (Takara Bio, Inc., Tokyo, Japan) according to the manufacturer's protocol. LDH activity was determined by measuring absorbance at $490 \mathrm{~nm}$, using a microplate reader (Spectra Max M2, Molecular Devices, Sunnyvale, CA, USA).

\subsection{Western blot assay}

Treated Cells were washed in cold PBS, harvested by re-suspending

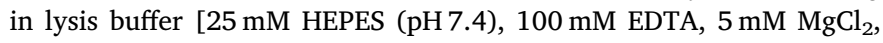


A

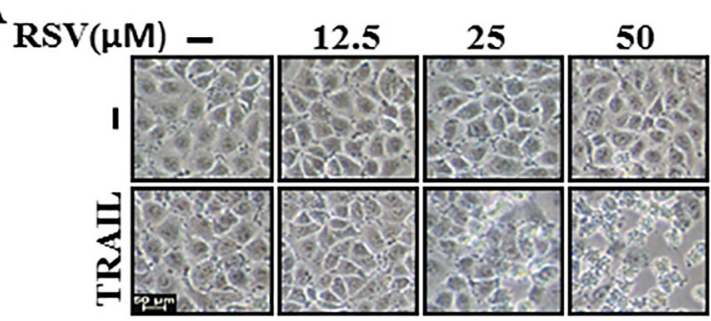

B

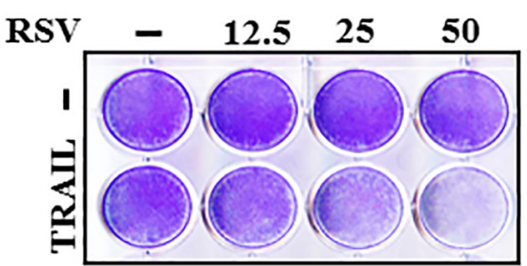

C

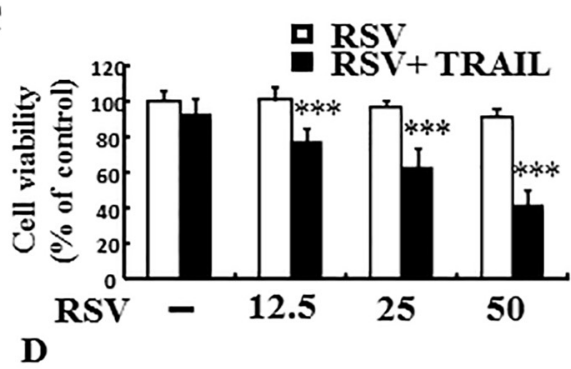

D

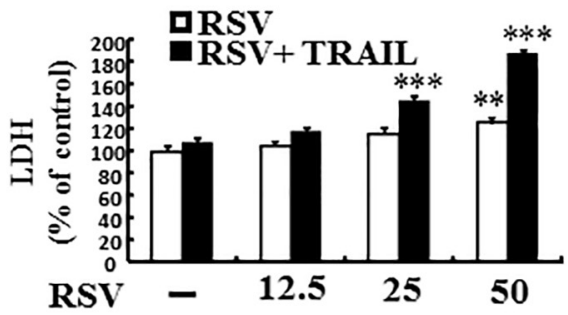

\section{$\mathbf{E}$}

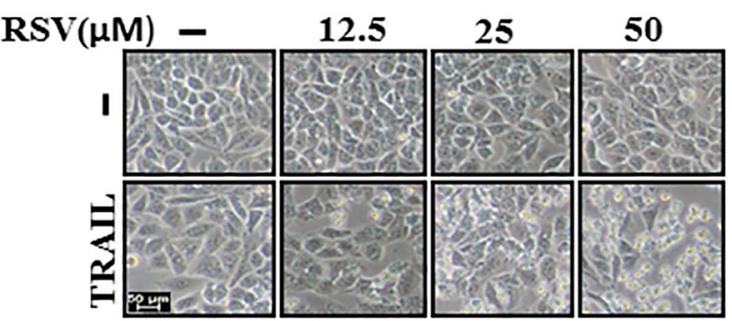

$\mathbf{F}$

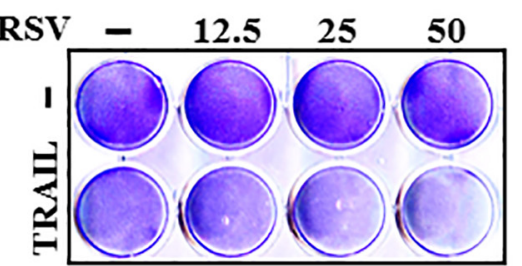

G

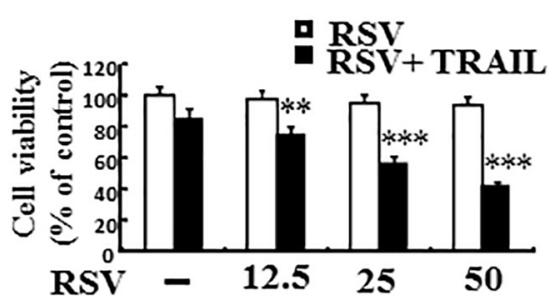

H
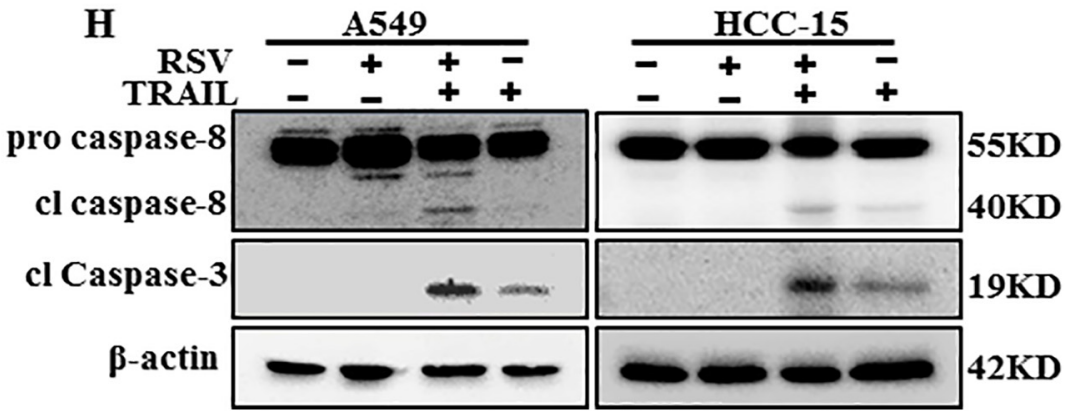

Fig. 1. Resveratrol enhances TRAIL-mediated apoptosis in A549 and HCC-15 cells.

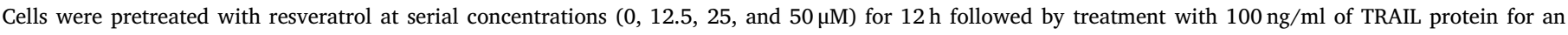

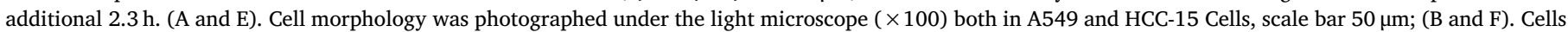

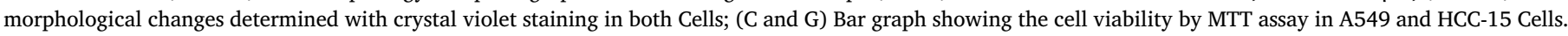

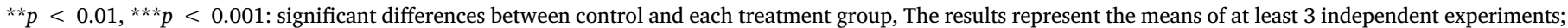

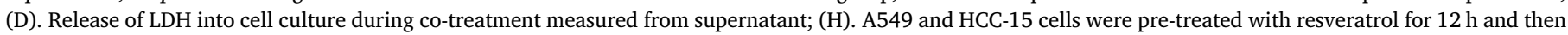

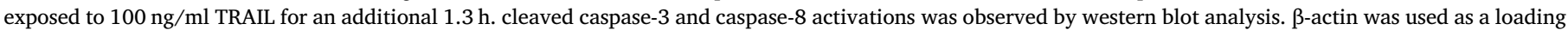
control; RSV-Resveratrol. (For interpretation of the references to colour in this figure legend, the reader is referred to the web version of this article.)

$0.1 \mathrm{mM}$ DTT, and a protease inhibitor cocktail], or using a Nuclear/ Cytosol Fractionation kit 261 (BioVision, Milpitas, CA, USA) and sonicated to prepare A549 cell lysates. Proteins $(20-35 \mu \mathrm{g})$ were separated in $10 \%-15 \%$ SDS gels and transferred onto nitrocellulose membranes. After incubation with an indicated concentration of primary antibody in dilution buffer ( $1 \%$ milk with PBS-Tween) and secondary antibody (1:5000) membranes were developed with enhanced chemiluminescence reagents. Primary antibodies (1:1000) were used for immunoblotting: LC3 (L8918), p62 (P0067) Sigma-Aldrich (St. Louis, MO, USA); pNF-кB (p65) (S3033), cleaved caspase-3 (9611-Cell Signaling Technology, Danvers, MA, USA); acetyl p53 (epitomics-2458-1); PUMA (PC686 CALBIOCHEM); p53 (SC-126), Bcl-2 (SC-7382), Bcl xl (SC7190), and Bax (SC-493), dilution (1:500), Santa Cruz Biotechnology, Inc. (Santa Cruz, CA, USA); cytochrome $c$ (BD556433), caspase-8 (BD 551243) (BD pharmingen, USA); pAkt (abcam-ab81283) and $\beta$-actin Sigma-Aldrich (A5441) (1:10000) (St. Louis, MO, USA). Images were obtained using a Fusion-FX7 imaging system (Vilber Lourmat, Marnela-Vallée, France). For each blots we confirmed the data at least 3/4 independent experiments.

\subsection{TEM (transmission electron microscopy) analysis}

TEM samples were analyzed by Transmission Electron Microscope (JEM-2010, JEOL) installed in the Center for University-Wide Research Facilities (CURF) at Chonbuk National University. After fixation of samples in $2 \%$ glutaraldehyde (EMS, USA) and $2 \%$ paraformaldehyde (EMS, USA) in 0.05 sodium cacodylate buffer (pH 7.2) (EMS, USA), specimens were post fixed in $1 \%$ osmium tetroxide (EMS, USA), dehydrated in graded ethanol and propylene oxide (EMS, USA). The cells were embedded in Epoxy resin (Embed 812, NMA; Nadic methyl anhydride, DDSA; Dodecyl Succinic Anhydride, DMP-30) (EMS, USA). Ultrathin sections were cut on an LKB-III ultratome (LEICA, Austria) and were stained with $0.5 \%$ uranyl acetate (EMS, USA) and lead citrate (EMS, USA). The images were taken on a Hitachi H7650 electron microscope (Hitachi, Japan) at an accelerating voltage of $100 \mathrm{kV}$.

\subsection{BacMam transduction}

Wild-type or mutant GFP-tagged LC3B was expressed in cells by 

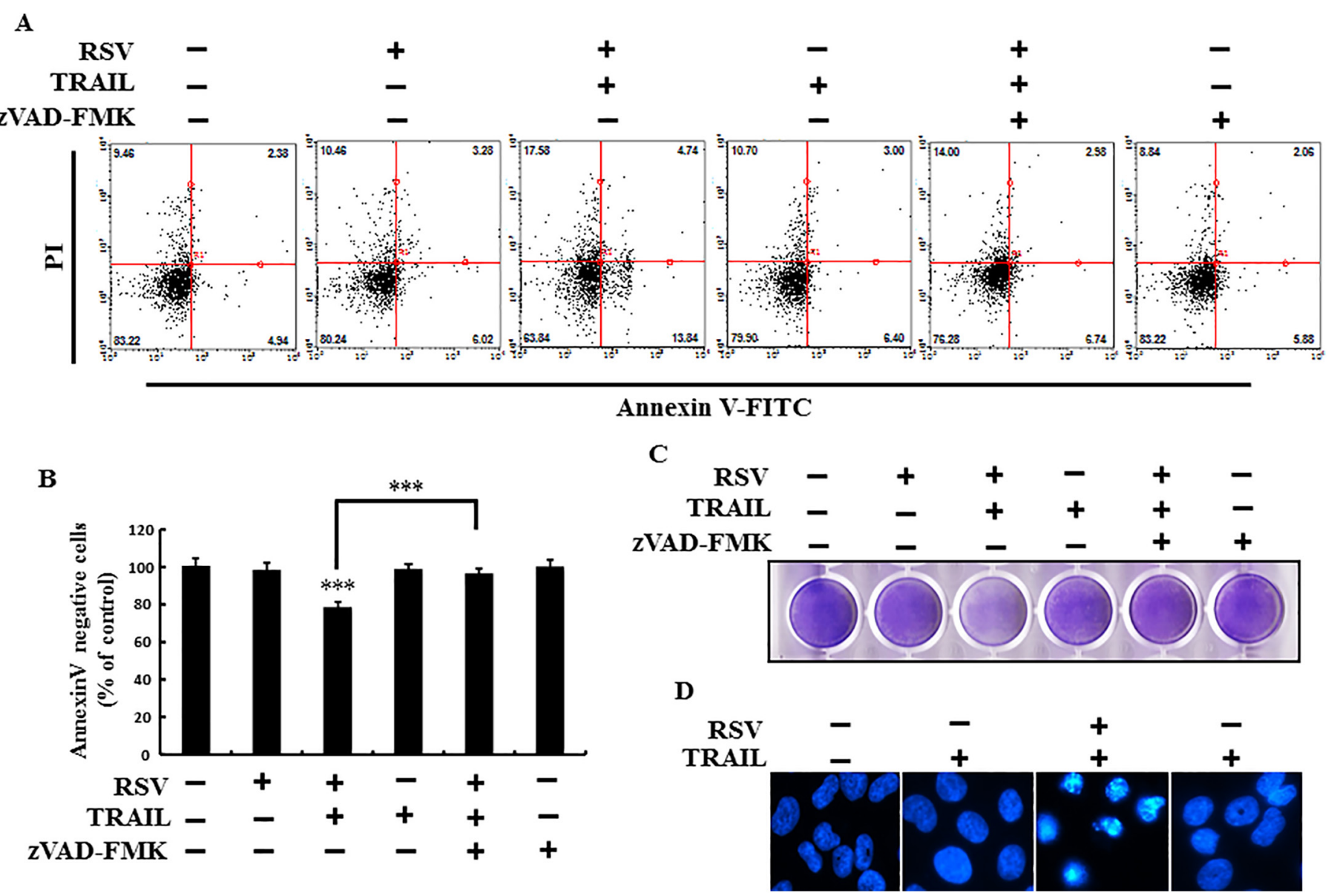

Fig. 2. Resveratrol enhances TRAIL-mediated apoptosis.

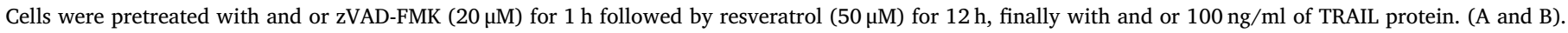

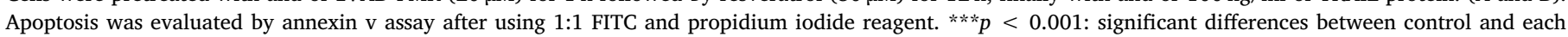

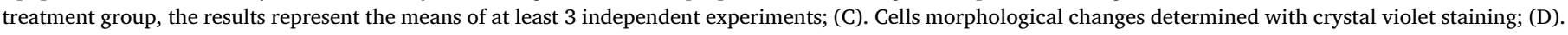

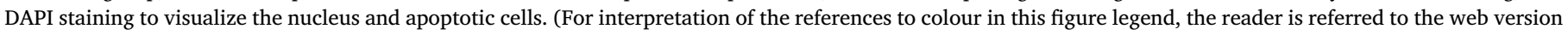
of this article.)

adding the appropriate concentrations of the appropriate virus from the Premo Autophagy Sensor LC3B-GFP kit (BacMam 2.0) (Life Technologies P36235) to the growth medium as indicated in the figure legends.

\subsection{Quantitative real-time polymerase chain reaction ( $q R T-P C R$ )}

Total ribonucleic acid (RNA) was extracted from A549 cells using the easy-spin ${ }^{\mathrm{TM}}$ Total RNA Extraction Kit (Intron Biotechnology, Seoul, Korea). The cDNA synthesis was carried out following the instructions in the TaKaRa PrimeScript TM 1st strand cDNA synthesis kit (TaKaRa Bio, Tokyo, Japan). For qRT-PCR, $1 \mu$ l of gene primers with SYBR Green (Bio-Rad Laboratories, Hercules, CA, USA) in $20 \mu$ of reaction volume was applied. The primers were: p62/SQSTM1 (forward: 5'CTCCCCAG ACTACGACTTGTGT3', reverse: 5'TCAACTTCAATGCCCAGAGG3'), and GAPDH (as an internal control) (forward: 5'GCAAGCAGGAGTATGAC GAG3', reverse: 5'CAAATAAAGCCATGCCAATC3'). All reactions with iTaq SYBR Green Supermix (Bio-Rad Laboratories, Hercules, CA, USA) were performed on the CFX96 real-time PCR detection system (Bio-Rad Laboratories, Hercules, CA, USA).

\subsection{RNA interference}

A549 cells were transfected with p53 small interfering RNA (siRNA ID 106140; ambion, by life Technologies Corporation) using
Lipofectamine 2000 transfection reagent (Invitrogen) according to the manufacturer's instructions. At 24-h post-transfection, the knockdown efficiency at protein level was determined by immunoblotting and cell viability test. Scrambled siRNA (ambion-4390843) was used as a negative control.

\subsection{Measurement of reactive oxygen species (ROS)}

The intracellular ROS generation was measured by staining the cells with $2^{\prime}, 7^{\prime}$-dichlorofluorescein-diacetate DCFH-DA. The fluorescent dye DCFH-DA is a cell membrane permeable and is converted into cell membrane impermeable non-fluorescent compound DCFH by intracellular esterase. Oxidation of DCFH by reactive oxygen species then produces a highly fluorescent DCF. The fluorescence intensity of DCF is proportional to the amount of peroxide produced. Briefly, A549 cells were treated with indicated concentration of resveratrol for $12 \mathrm{~h}$. After treatment, cells were rinsed with PBS, harvested and further incubated with $10 \mu \mathrm{M}$ DCFH-DA at $37^{\circ} \mathrm{C}$ for $30 \mathrm{~min}$. Finally, analyzed for $2^{\prime}, 7^{\prime}-$ dichlorofluorescein (DCF) fluorescence by flow cytometry.

\subsection{Mitochondrial membrane potential assay}

Resveratrol treated A549 cell were incubated in media containing $10 \mu \mathrm{M} \mathrm{JC}-1$ at $37^{\circ} \mathrm{C}$ for $30 \mathrm{~min}$ at RT, washed with PBS, and transferred to a clear 96-well plate. J-aggregates in intact mitochondria were 
A

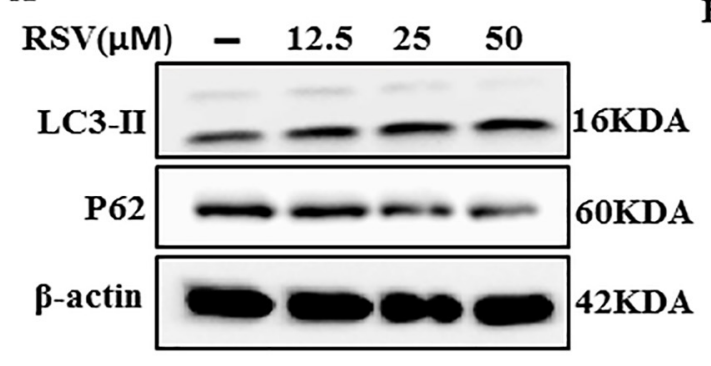

B

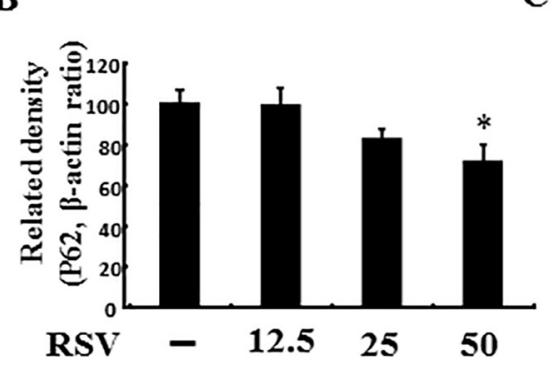

C

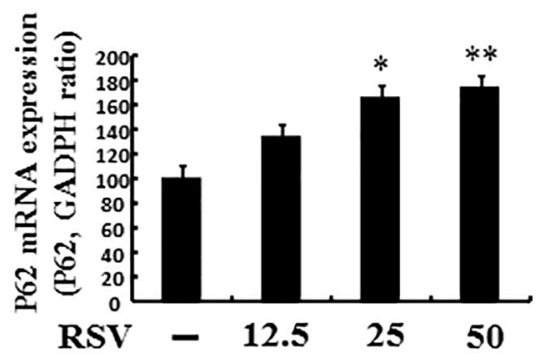

D

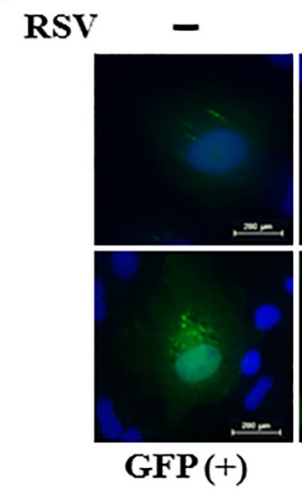

10

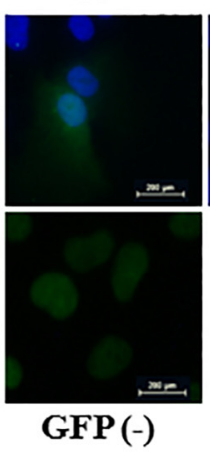

50

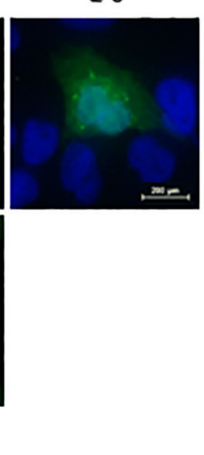

$\mathbf{E}$

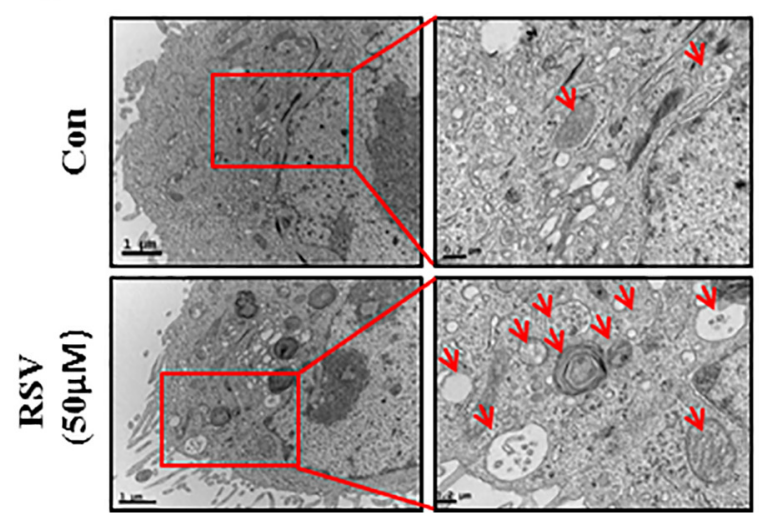

Fig. 3. Autophagy flux is induced by resveratrol treatment in A549 cells.

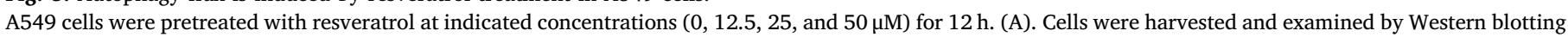

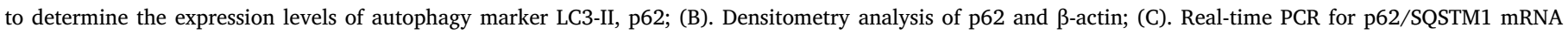

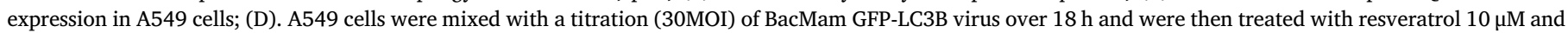

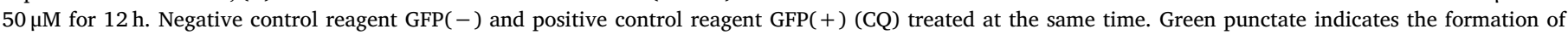

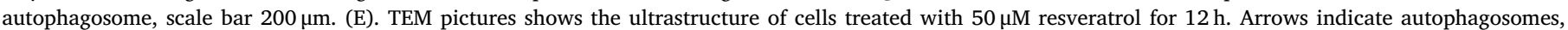

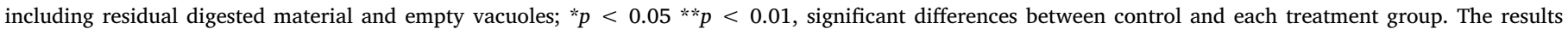

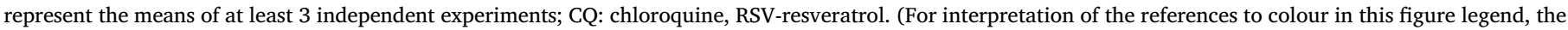
reader is referred to the web version of this article.)

evidence as red fluorescence with emission at $583 \mathrm{~nm}$, excitation $490 \mathrm{~nm}$ indicating high or normal MMP. Green fluorescence with emission at $525 \mathrm{~nm}$, excitation $490 \mathrm{~nm}$ indicates low MMP when JC-1 remains in the monomeric form in the cytoplasm. A549 cells were cultured onto coverslips in a 24 -well plate, incubated in media containing $10 \mu \mathrm{M} \mathrm{JC}-1$ at RT for $30 \mathrm{~min}$ in dark condition, and washed with PBS. Finally, cells were mounted with DakoCytomation fluorescent medium (Dako, Carpinteria, CA, USA) and visualized under a fluorescence microscope.

\subsection{Statistical analysis}

All data are expressed as means \pm standard deviation (SD). For multiple comparisons, one-way analysis of variance (ANOVA) followed by the Tukey-Kramer test was used. All statistical analysis was performed using GraphPad Prism software. Statistical significance was indicated by a $P$ value $<0.05(*), 0.01\left(^{* *}\right)$, or $0.001\left(^{* * *}\right) . n=3$.

\section{Results}

3.1. Resveratrol enhances TRAIL-mediated apoptosis in lung adenocarcinoma A549 and HCC-15 cells

The effects of resveratrol on TRAIL-induced apoptosis were demonstrated using two lung adenocarcinoma cell lines. A549 and HCC15 cells were pretreated with serial concentrations of resveratrol for
$12 \mathrm{~h}$ followed by treatment with and or TRAIL protein for an additional $2.3 \mathrm{~h}$. Changes in cell morphologies were confirmed under a light microscope to determine viable treatment conditions. As shown in Fig. 1, treatment of resveratrol or TRAIL alone only slightly affected cell viability, since minor morphological changes were observed when compared to the control group, therefore indicating that A549 and HCC-15 cells were resistant to TRAIL. However, co-treatment of TRAIL with different concentrations of resveratrol significantly reduced cell viability as shown by the observation of apoptotic cell morphologies (Fig. 1A, B, E and F). The combined treatment of TRAIL with resveratrol decreased cell viability and increased the percentage of A549 and HCC15 cells undergoing apoptosis (Fig. 1C and G). The lactate dehydrogenase (LDH) levels in A549 cells demonstrated that resveratrol induced apoptosis in a dose-dependent manner when combined with TRAIL, whereas resveratrol by itself did not induce cell death (Fig. 1D). The combination treatment of TRAIL and resveratrol activates cleaved caspase- 8 and 3 compared with the single treatment of either resveratrol or TRAIL in both A549 and HCC-15 cells (Fig. 1H). Furthermore, AnexinV negative cells or viable cells percentage was lower in combined treatment of resveratrol and TRAIL than treatment with TRAIL or resveratrol alone. Pan-caspase inhibitor zVAD-FMK eliminated the apoptotic percentage of combined treated cells and higher the viable conditions (Fig. 2A-C). DAPI staining showed the apoptotic cells in resveratrol and TRAIL combined treatment while treatment alone found almost viable cells (Fig. 2D).

Collectively, these results indicated that resveratrol with exposure 

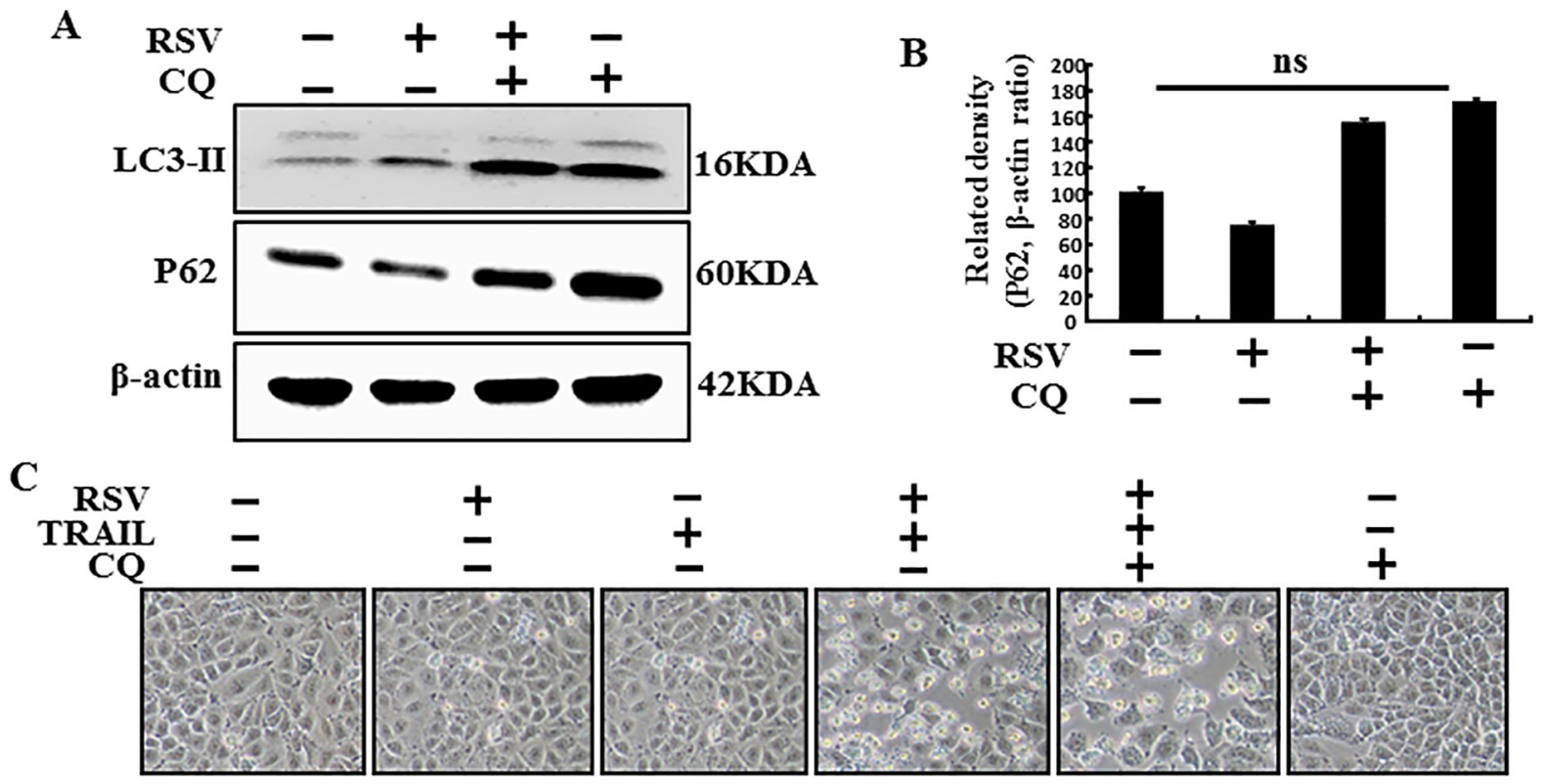

D

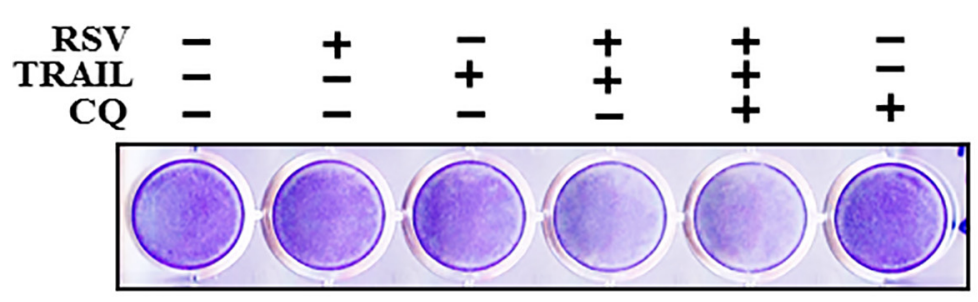

$\mathbf{E}$

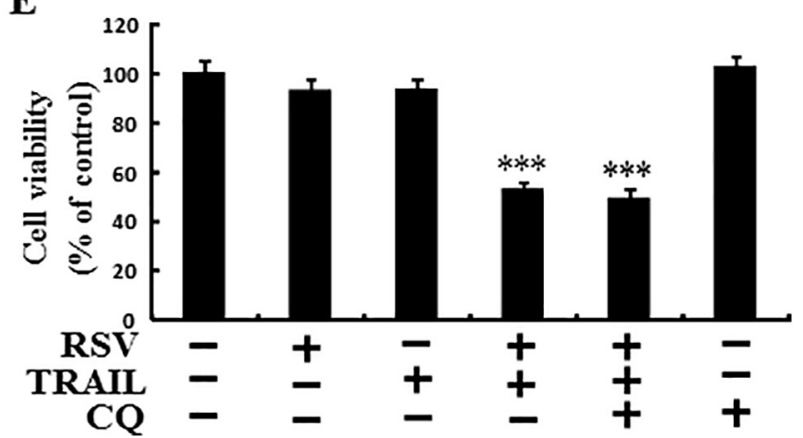

Fig. 4. Resveratrol induced TRAIL-mediated apoptosis is not influenced by autophagy inhibitor.

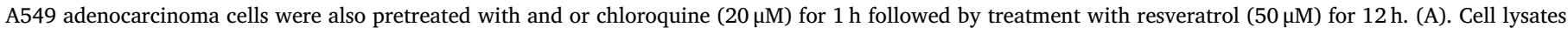

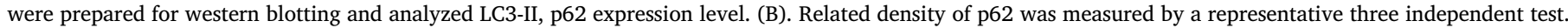

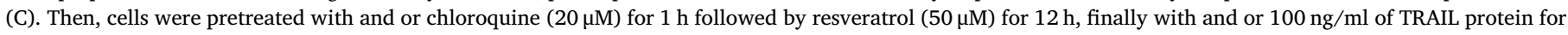

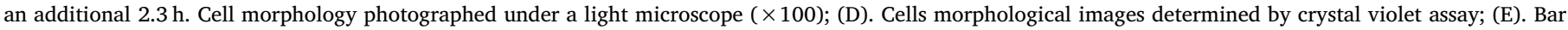

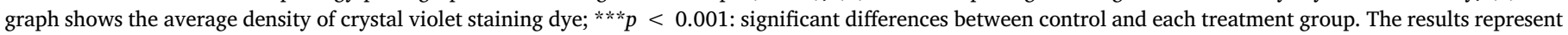

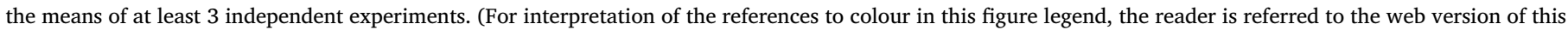
article.)

of TRAIL treatment induces TRAIL-mediated apoptosis in TRAIL-resistant human lung adenocarcinoma A549 and HCC-15 cells.

\subsection{Autophagy flux is induced by resveratrol treatment in A549 cells}

To evaluate the effects of resveratrol on the induction of autophagy flux, A549 cells were pretreated with different concentrations of resveratrol for $12 \mathrm{~h}$. Cell lysates were then used for western blot analysis. The formation of the autophagosome is mediated by the Atg12-Atg5Atg16 complex and microtubule -associated protein light chain 3 (LC3I)-phospholipid conjugates (LC3-II). P62 is the well-known autophagy substrate; 662 is incorporated with autophagosomes by interacting with LC3 and is efficiently degraded by autophagy. As shown in Fig. 3A, the conversion rate of LC3-I to LC3-II increased as evidenced by the formation of autophagosomes. Furthermore, p62 expression decreased as a result of resveratrol treatment in a dose-dependent manner, therefore indicating a complete activation of autophagy flux via lysosomal degradation. Densitometry analysis indicated down expression of $\mathrm{p} 62$ (Fig. 3B). Additionally, increases in p62/SQSTM1 mRNA expression in A549 cells treated with resveratrol in a dose-dependent manner were also observed, therefore demonstrating the activation of autophagy flux (Fig. 3C). As shown in Fig. 3D, A549 cells treated with resveratrol showed increased amounts of punctate, therefore suggesting the activation of autophagy. Finally, transmission electron microscopy was performed to confirm the formation of double-membrane autophagosome, which contained numerous autophagic vacuoles and empty vacuoles in cells treated with $50 \mu \mathrm{M}$ of resveratrol, whereas very few vacuoles were observed in untreated cells (Fig. 3E). These findings suggest that resveratrol could induce autophagy in TRAIL-resistant A549 cells.

\subsection{Resveratrol induced TRAIL-mediated apoptosis is not influenced by autophagy inhibitor}

To confirm the role of autophagy in resveratrol induced TRAILmediated apoptosis, we investigated the effect of chloroquine on A549 cells (Fig. 4). A549 cells were treated with chloroquine for $1 \mathrm{~h}$, followed by a resveratrol treatment for $12 \mathrm{~h}$. Cell lysates were used for western blotting to determine changes in LC3-II and p62 expression levels. Autophagy induction was demonstrated by the confirmation of 

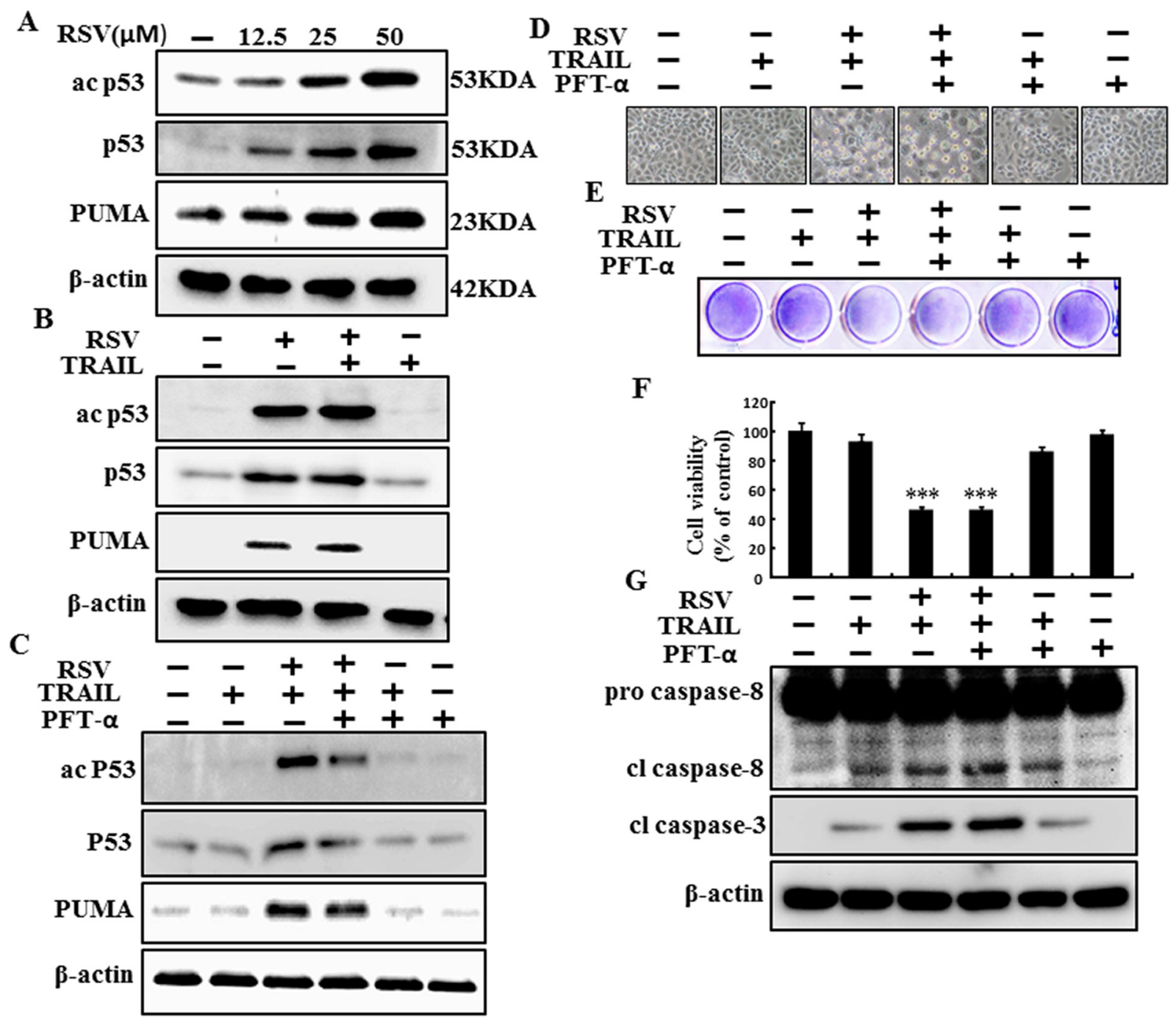

Fig. 5. Resveratrol-enhanced TRAIL-mediated apoptosis is independent of p53.

A549 cell were treated with resveratrol concentrations of $(0,12.5,25$, and $50 \mu \mathrm{M})$ for $12 \mathrm{~h}$ then incubated additional $1.3 \mathrm{~h}$ and or with TRAIL protein $(100 \mathrm{ng} / \mathrm{ml})$ (A). The expression of ac p53, p53, PUMA in resveratrol treatment; (B). Overexpression of p53 \& PUMA observed in combined treatment. Again, cells were pretreated with PFT $\alpha(40 \mu \mathrm{M})$ for $1 \mathrm{~h}$ followed by treated with resveratrol $(50 \mu \mathrm{M})$ for $12 \mathrm{~h}$, then treated with and or TRAIL protein for an additional $1.3 \mathrm{~h}$ for western blotting and $2.3 \mathrm{~h}$ for cell viability; (C, G). Finally, cell lysates used for western blotting and analyzed the expressions of ac p53, p53, PUMA, cleaved caspase-8 and caspase-3; (D). Cell morphology was photographed under a light microscope $(\times 100)$; (E). Cells morphological changes examined with crystal violet staining in A549 Cells; (F). Bar diagram evaluated the cell viability with MTT assay in A549 Cells; ***p $<0.001$ : significant differences between control and each treatment group. The results represent the means of at least 3 independent experiments. CQ- Chloroquine. PFT $\alpha$ - Pifithrin- $\alpha$; ac p53- Acetyl p53; PUMA- p53 upregulated modulator of apoptosis. (For interpretation of the references to colour in this figure legend, the reader is referred to the web version of this article.)

autophagy flux in cells treated with resveratrol. Furthermore, chloroquine treatment resulted in the accumulation of membrane-bound LC3-II and p62, which were not observed in the control group (Fig. 4A and B). Then, A549 cells were treated with chloroquine for $1 \mathrm{~h}$, and then treated with resveratrol for $12 \mathrm{~h}$, followed by a TRAIL treatment for an additional $2.3 \mathrm{~h}$. As an autophagy inhibitor, chloroquine was unable to abolish or enhances the cell death, which was induced by the combined treatment of resveratrol and TRAIL during autophagy activation. Cell death was observed as demonstrated by cell morphological changes and crystal violet staining in cells treated with both resveratrol and TRAIL (Fig. 4C and D). Furthermore, chloroquine did not have an effect on apoptosis that was initiated by resveratrol and TRAIL treatments, as indicated by the percentage of viable cells remaining (Fig. 4E). Overall, TRAIL-mediated apoptosis induced by resveratrol is not influenced by an autophagy inhibitor.

\subsection{Resveratrol-enhanced TRAIL-mediated apoptosis is independent of p53}

To investigate the molecular mechanism resulting in A549 cell death via co-treatment with resveratrol and TRAIL, we analyzed the contribution of p53 to apoptosis (Fig. 5). A549 cells were pretreated with different concentrations of resveratrol for $12 \mathrm{~h}$ and then additionally treated with and or TRAIL protein for $1.3 \mathrm{~h}$. Western blotting revealed that Resveratrol treatment increased the expression levels of tumor suppressor proteins acetyl p53, p53, and PUMA (Fig. 5A). The combined treatment of resveratrol and TRAIL further increased the expression levels of acetyl p53, p53, and PUMA when compared to cells treated with only resveratrol (Fig. 5B). Pifithrin- $\alpha$, a pharmacological inhibitor of p53, was used to confirm the expression of p53 acetylation, p53, and PUMA. Through immunoblotting, we observed that pretreatment of pifithrin- $\alpha$ suppresses the p53 acetylation, p53, and PUMA expression (Fig. 5C). To investigate the role of p53 in the apoptotic cascade, cells were treated with and or pifithrin- $\alpha$ for $1 \mathrm{~h}$, followed by resveratrol in an indicated concentration for $12 \mathrm{~h}$, and finally treated 
$\mathbf{A}$
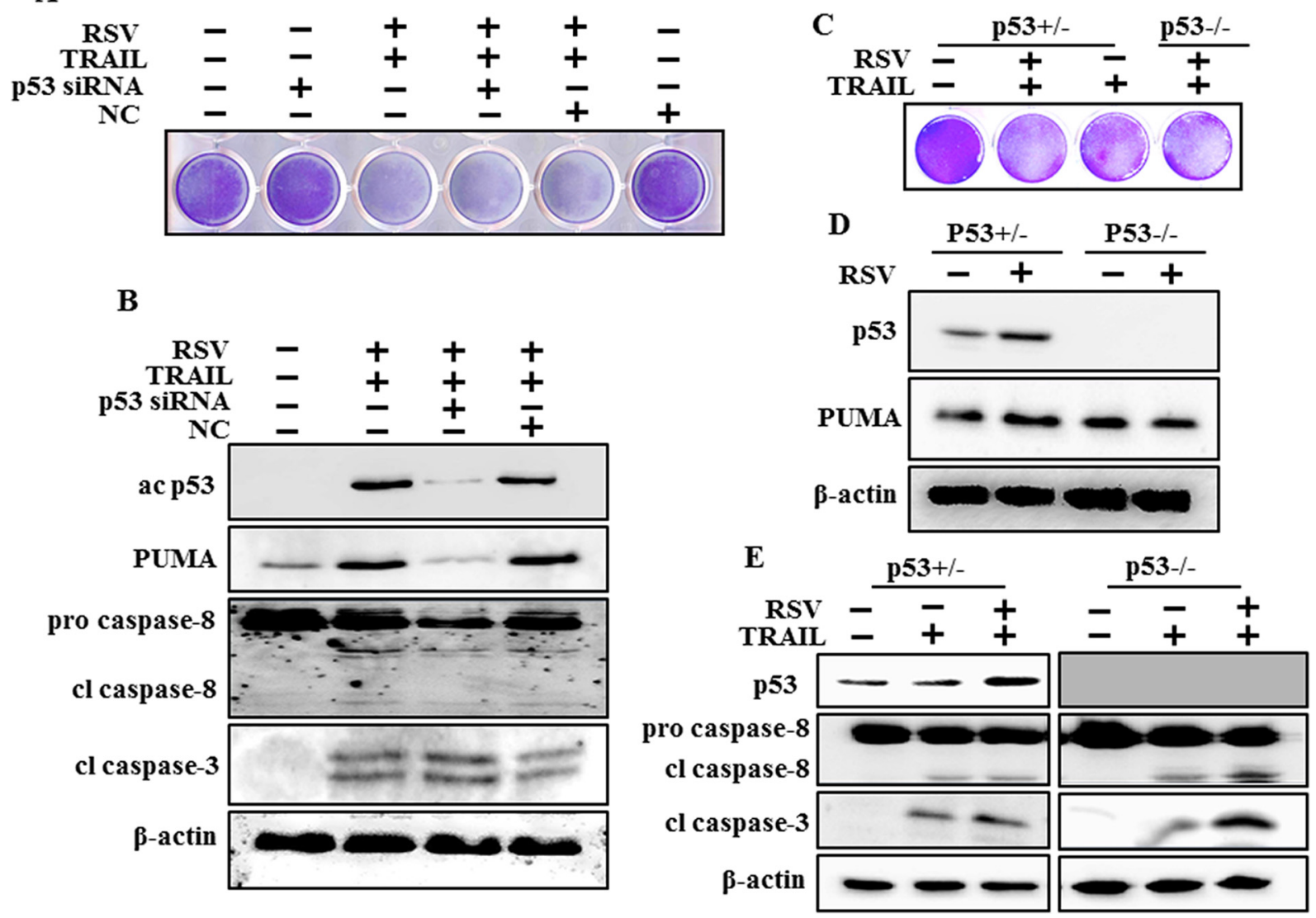

Fig. 6. Knockdown of p53 is unable to block apoptosis.

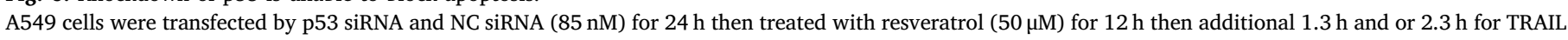

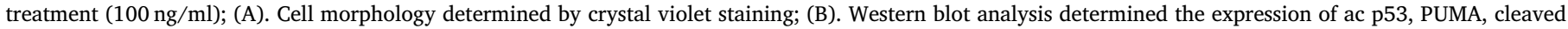

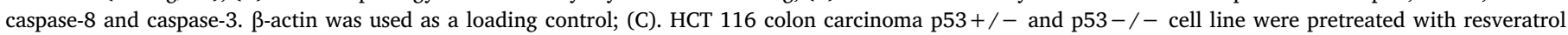

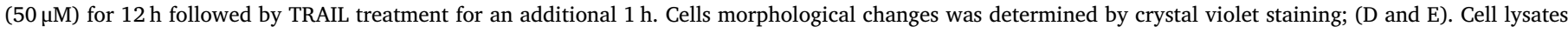

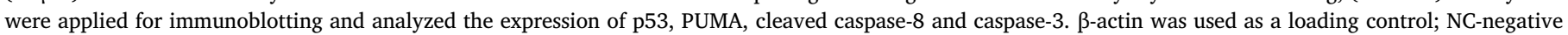
control. (For interpretation of the references to colour in this figure legend, the reader is referred to the web version of this article.)

with TRAIL protein for an additional $2.3 \mathrm{~h}$. Blocking of cell death was not observed as demonstrated by a lack of morphological changes and crystal violet staining in cells treated with pifithrin- $\alpha$, resveratrol and TRAIL compared to the pifithrin- $\alpha$ untreated group, therefore demonstrating that pifithrin- $\alpha$ had no influence on cell death induced by resveratrol and TRAIL co-treatment (Fig. 5D and E). Furthermore, no differences were observed in the percentage of viable cells in the pifithrin $\alpha$-treated group when compared to the pifithrin- $\alpha$ untreated group (Fig. 5F). Pifithrin- $\alpha$ also did not attenuate the activation and function of cleaved caspase- 8 and caspase- 3 that was initiated by the resveratrol and TRAIL co-treatment (Fig. 5G). Overall, these findings suggest that resveratrol-induced TRAIL-mediated apoptosis is independent of $\mathrm{p} 53$.

\subsection{Knockdown of p53 is unable to block apoptosis}

To confirm the role of resveratrol in TRAIL-mediated apoptosis, we used a p53 knockout cell line as well as cells treated with p53 siRNA, which surely confirmed that p53 or PUMA did not maintain apoptotic stimulation (Fig. 6). A549 cells were transfected with p53 siRNA or a negative control siRNA (NC) for $24 \mathrm{~h}$ and then treated with $50 \mu \mathrm{M}$ resveratrol for $12 \mathrm{~h}$ with and or TRAIL protein $(100 \mathrm{ng} / \mathrm{ml})$ for an additional $2.3 \mathrm{~h}$. We observed that p53 siRNA transfected co-treated cells did not block cellular apoptosis which was induced by resveratrol and TRAIL co-treatment. Furthermore, treatment with only the p53 siRNA or negative control siRNA had no effect on cell morphology (Fig. 6A).
Next, cells that were transfected with p53 siRNA were treated with resveratrol for $12 \mathrm{~h}$ then additionally with TRAIL for another $1.3 \mathrm{~h}$. We observed that acetyl p53 and PUMA were downregulated in cells transfected with the p53 siRNA following co-treatment with resveratrol and TRAIL protein when compared to the non-transfected group. However, caspase- 8 and cl-caspase- 3 were not blocked in cells transfected with the p53 siRNA (Fig. 6B). Next, we used a p53 knockout cell line to evaluate the role of p53 in resveratrol-induced TRAIL-mediated apoptosis to confirm the results observed with the p53 siRNA. Cells were pretreated with resveratrol for $12 \mathrm{~h}$, followed by additional treatment with TRAIL for $1 \mathrm{~h}$. When we analyzed for cell viability, no significant differences were observed in the p53 knockout cells when compared to wild-type cells after treatment with resveratrol and TRAIL (Fig. 6C). Moreover, in western blot analysis $\mathrm{p} 53^{+/-}$and $\mathrm{p} 53^{-/-}$ HCT116 human colon carcinoma cells that were co-treated with resveratrol and TRAIL showed block the expression of p53 and PUMA when compared to wild-type cells (Fig. 6D). Finally, caspase-8 and cleaved caspase- 3 were also activated in both p53 wild-type and knockout cell lines (Fig. 6E). Overall, these results demonstrate that knockdown of p53 is unable to block resveratrol induced TRAILmediated apoptosis.

\subsection{Downregulation of $N F-\kappa B$ (p65) by resveratrol attenuates TRAIL resistance}

To demonstrate exact the molecular mechanisms that are related to 
A

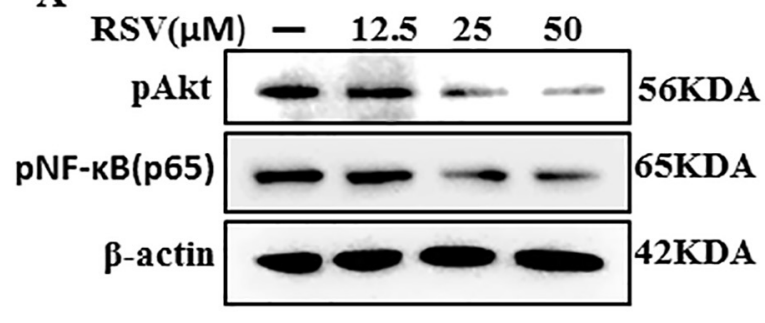

B
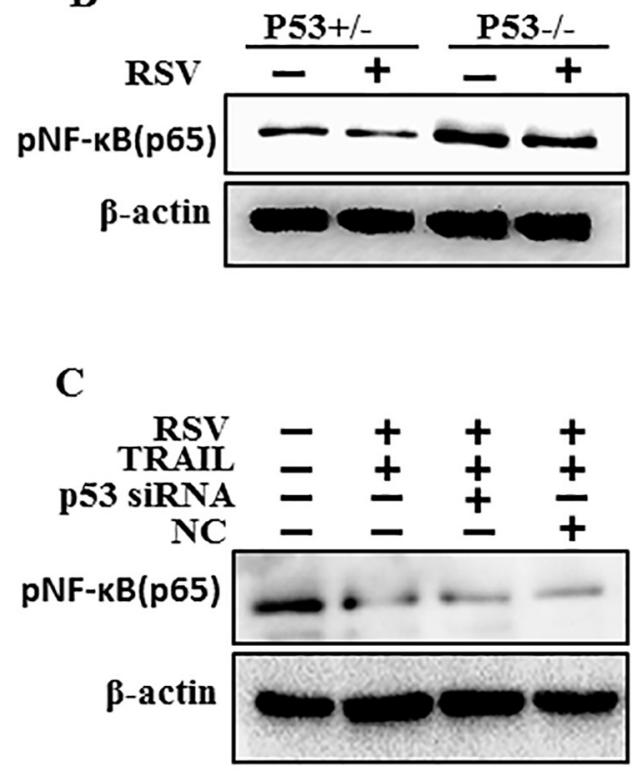

D

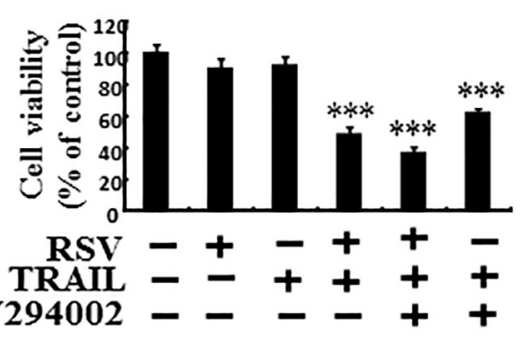

$\mathbf{E}$

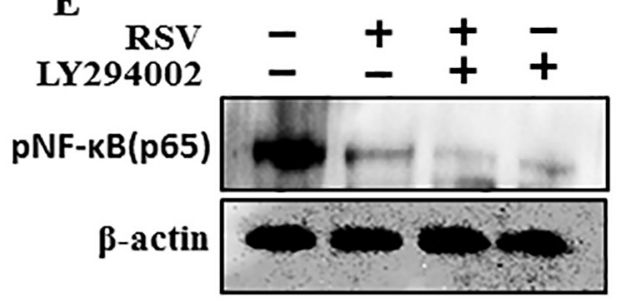

$\mathbf{F}$ $\operatorname{RSV}(\mu \mathrm{M})-\quad 12.5 \quad 25 \quad 50$

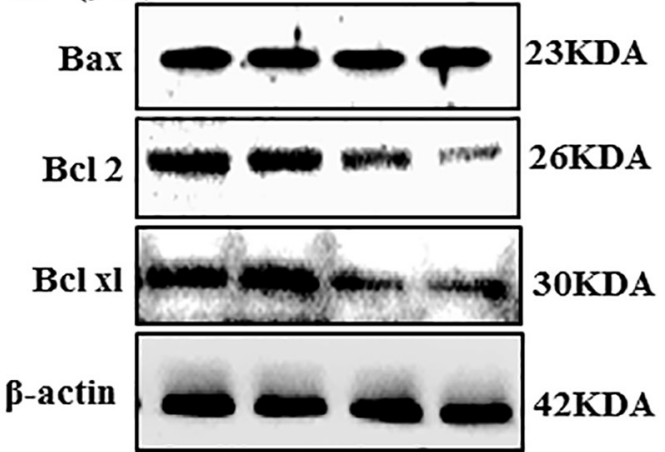

Fig. 7. Downregulation of NF-kB (p65) by resveratrol attenuates TRAIL resistance.

A549 cells were pretreated with resveratrol by the serial concentration of $(12.5,25,50 \mu \mathrm{M})$ for $12 \mathrm{~h}$. (A and G). Cell lysates were used for western blotting and observed the expression level of pAkt, pNF-kB (p65), Bax, Bcl-2, Bcl-xl dose-dependently; (B). p53 knockout cell line was treated with $50 \mu \mathrm{M}$ resveratrol for $12 \mathrm{~h}$ and observed the expression level of pNF-kB (p65) by western blotting; (C). Cells were transfected with p53 siRNA and/or NC siRNA ( $85 \mathrm{nM)} \mathrm{for} 24 \mathrm{~h}$ then treated with resveratrol $12 \mathrm{~h}$ followed by $1.3 \mathrm{~h}$ additional TRAIL ( $100 \mathrm{ng} / \mathrm{ml}$ ) treatment and expression level of pNF-kB (p65) was determined by immunoblotting; (D). pNF- $\mathrm{kB}$ (p65) activity was measured by resveratrol $(50 \mu \mathrm{M})$ and TRAIL $100 \mathrm{ng} / \mathrm{ml}$ combined treatment; (E). Cells were pretreated with $\mathrm{LY} 294002$ for $1 \mathrm{~h}$ then treated with and or resveratrol $(50 \mu \mathrm{M})$ for $12 \mathrm{~h}$ finally additional $2.3 \mathrm{~h}$ for TRAIL $(100 \mathrm{ng} / \mathrm{ml})$ treatment. Bar diagram showing the average density of MTT assay in A549 Cells; ${ }^{* * *} p<0.001$ : significant differences between control and each treatment group. The results represent the means of at least 3 independent experiments; (F). Cells

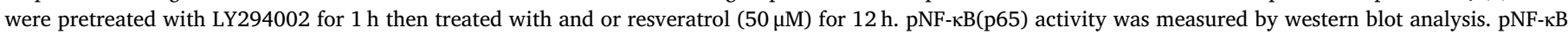
(p65)-nuclear factor kappaB, Bcl-2-B-cell lymphoma 2 protein, Bax-Bcl-2 associated X protein.

resveratrol induced TRAIL-mediated apoptosis in A549 cells, we performed further immunoblotting (Fig. 7). Cells that were pretreated with resveratrol as described above showed that resveratrol decreases the expression of phosphorylated Akt-mediated suppression of NF- $\mathrm{B}$ (p65) in a dose-dependent manner (Fig. 7A). Furthermore, we confirmed the relation between NF- $\mathrm{KB}$ (p65) and $\mathrm{p} 53$ by using p53 siRNA and a p53 knockout cell line. Lysate from resveratrol-treated $\mathrm{p} 53^{+/-}$and $\mathrm{p} 53^{-/-}$ cells were applied for immunoblotting, and we observed that NF-kB (p65) was inactivated when compared to control cells in both cell line (Fig. 7B). Furthermore, p53 siRNA and NC siRNA treatments also showed inactivation of NF- $\mathrm{kB}(\mathrm{p} 65)$ when compared to untreated cells proved NF-kB (p65) signaling did not regulate by p53 (Fig. 7C). Next, LY294002 was used and the result showed that LY294002 pretreated resveratrol and TRAIL co-treated cells undergo more apoptosis than resveratrol and or TRAIL treated alone. Western blot result also observed higher blocking of NF-kB (p65) in LY294002 and resveratrol cotreatment than mono-treatment. These data confirmed the potential relationship to decreasing the expression of phosphorylated Akt-mediated suppression of NF-kB (p65) by resveratrol (Fig. 7D and E). We then focused on Bcl-2 and Bcl-xl, both of which localize to the mitochondrial outer membrane. Here, they play a significant role in promoting cell survival and inhibiting Bax and Bak, both of which promote permeabilization and the release of cytochrome $c$ for the initiation of apoptosis. Cells were pretreated with resveratrol as described above, and cell lysates were applied for immunoblotting. Both Bcl-2 and Bcl-xl were significantly downregulated in a dose-dependent manner, whereas Bax remains unchanged (Fig. 7F). Overall, we confirmed that the suppression of NF-kB (p65) by resveratrol attenuates TRAIL resistance and enhances TRAIL-mediated apoptosis via inhibition of anti-apoptotic signals.

\subsection{Cytochrome c translocation through mitochondrial dysfunction by resveratrol sensitizes TRAIL}

Next, we confirmed the mitochondrial integrity by investigating the mitochondrial membrane potential (MMP) during the initiation of apoptosis (Fig. 8). Cells were pretreated with resveratrol for $12 \mathrm{~h}$, followed by an additional $1.3 \mathrm{~h}$ treatment with and or TRAIL. JC-1, a lipophilic cationic dye, was used to determine the loss of MMP. In untreated cells, JC-1 normally aggregates within intact mitochondria and 
A

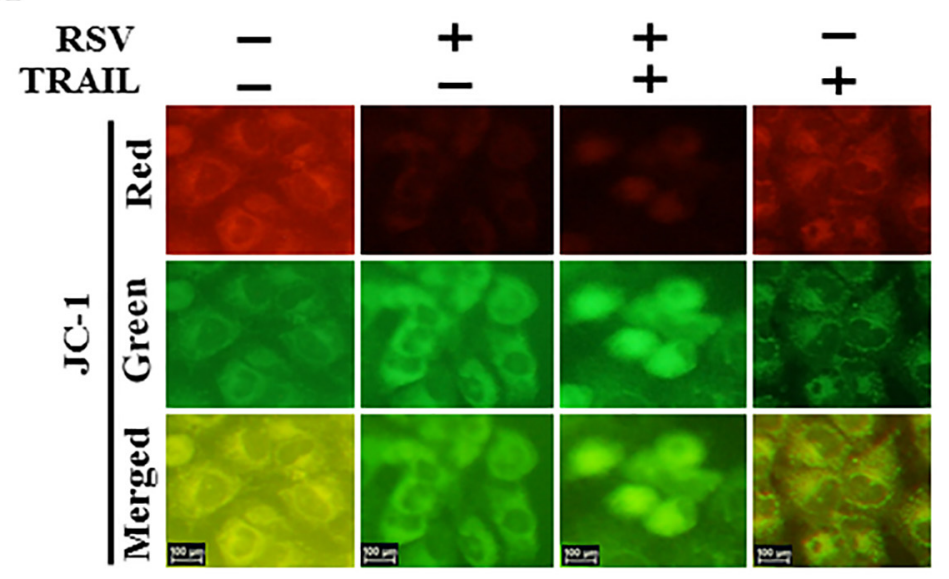

C

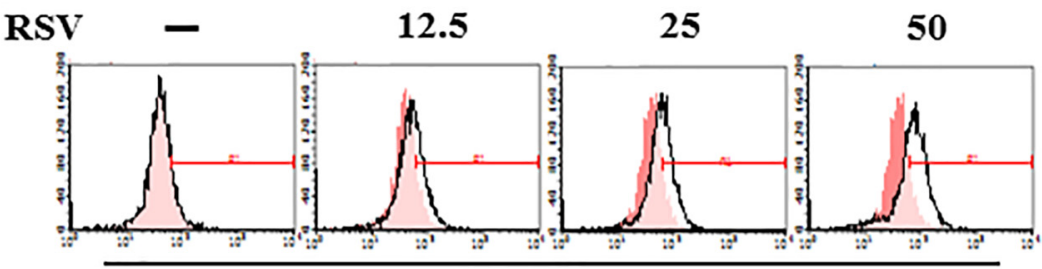

B

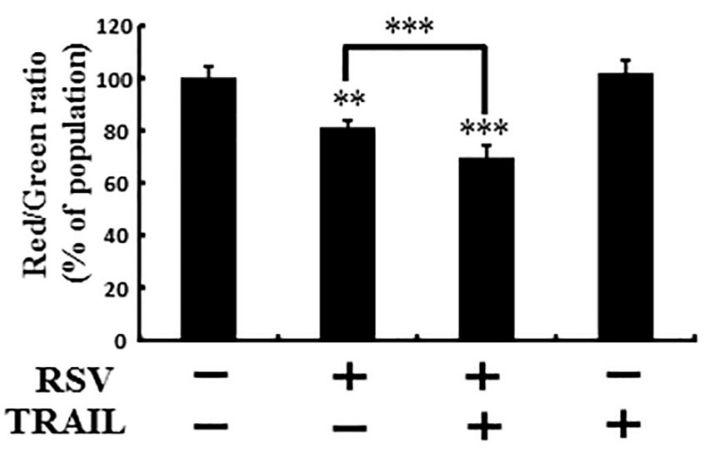

D

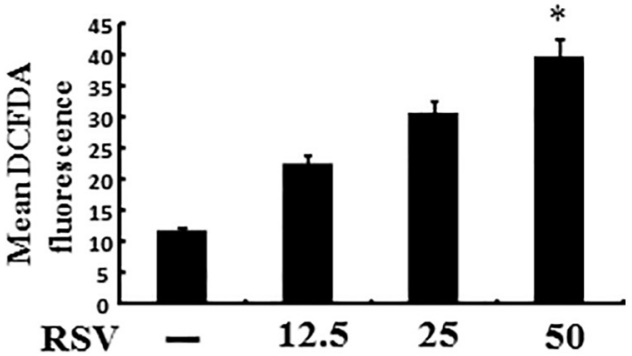

$\mathbf{E}$

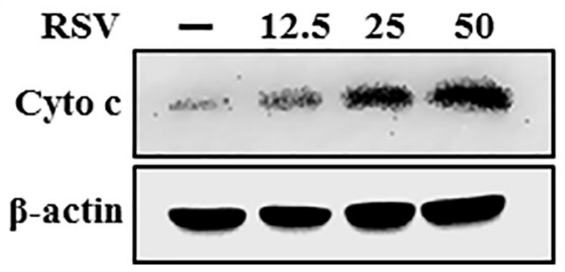

F Con RSV

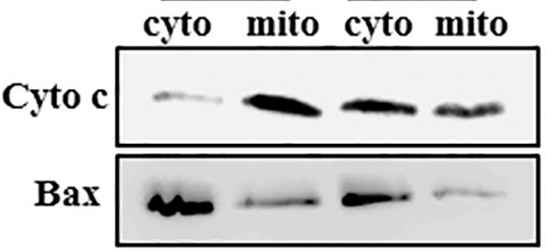

Fig. 8. Cytochrome $c$ translocation through mitochondrial dysfunction by resveratrol sensitizes TRAIL.

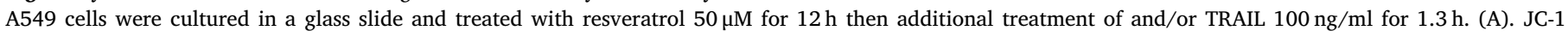

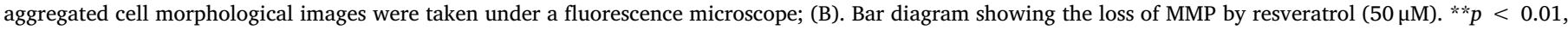

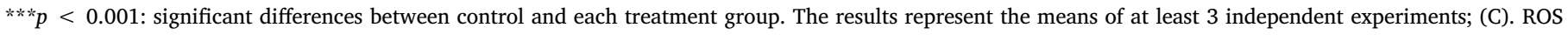

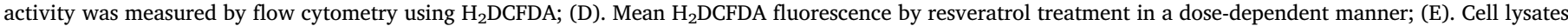

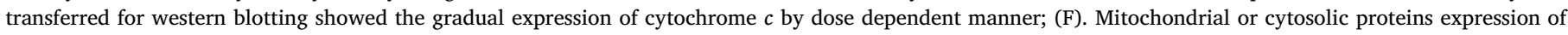
cytochrome $c$ and Bax were detected by western blot analysis.

emits a red fluorescence in untreated cells. These aggregates were mostly absent in cells treated with resveratrol, and resveratrol with TRAIL co-treated group. On the other hand, JC-1 produces green fluorescence was observed prominently in resveratrol and TRAIL cotreated group indicated the collapse of MMP due to mitochondrial dysfunction (Fig. 8A). The red-to-green fluorescent ratio confirmed the loss of MMP in cells that were co-treated (Fig. 8B). Furthermore, intracellular reactive oxygen species (ROS) generations were also observed in resveratrol treatment in a dose-dependent manner (Fig. 8C and D). Owing to mitochondrial damage in resveratrol-treated A549 cells, cytochrome $c$ was released dose-dependent manner and also translocation of cytochrome $c$ was observed from the mitochondria into the cytosol during resveratrol treatment. However, no changes in Bax localization were observed. In translocation test, it showed that RSV treatment Bax translocation into mitochondria was absent. So the Bax does not require in resveratrol induced TRAIL-mediated cell death (Fig. 8E and F).

Overall, resveratrol facilitates the TRAIL-based cancer treatment more active in human lung cancer cells by attenuating the phosphorylated Akt-mediated suppression of NF-kB, leads to mitochondrial dysfunction and cytochrome $c$ translocation (Fig. 9).

\section{Discussion}

Although numerous invasive and noninvasive therapeutic interventions have been developed for cancers, tumors still display highly complex behaviors and resistance to therapeutic actions. To meet the current demand for anticancer therapies, our goal was to demonstrate the molecular mechanisms underlying resveratrol induced TRAILmediated apoptosis in NSCLC. Herein, we conclude that a combination treatment using resveratrol and TRAIL is effective against TRAIL-resistant lung cancer cells via targeting Akt-mediated suppression of NF$\kappa \mathrm{B}$ (p65) activity which potentiates mitochondrial dysfunction and apoptosis.

Resveratrol, a polyphenolic compound has protective action against multiple types of cancers. Resveratrol also can reverse multidrug resistance when used in combination with clinically used drugs. Multiple studies found both intrinsic and extrinsic apoptotic pathways are involved in resveratrol induced apoptosis [50, 51]. TRAIL sensitizes a wide variety of cancer cells or transformed cells by apoptosis; however, TRAIL resistance in different cancer cells is a growing concern for cancer chemotherapies $[8,52,53]$. In our study, we also observed that a single treatment with resveratrol or TRAIL did not or only slightly 

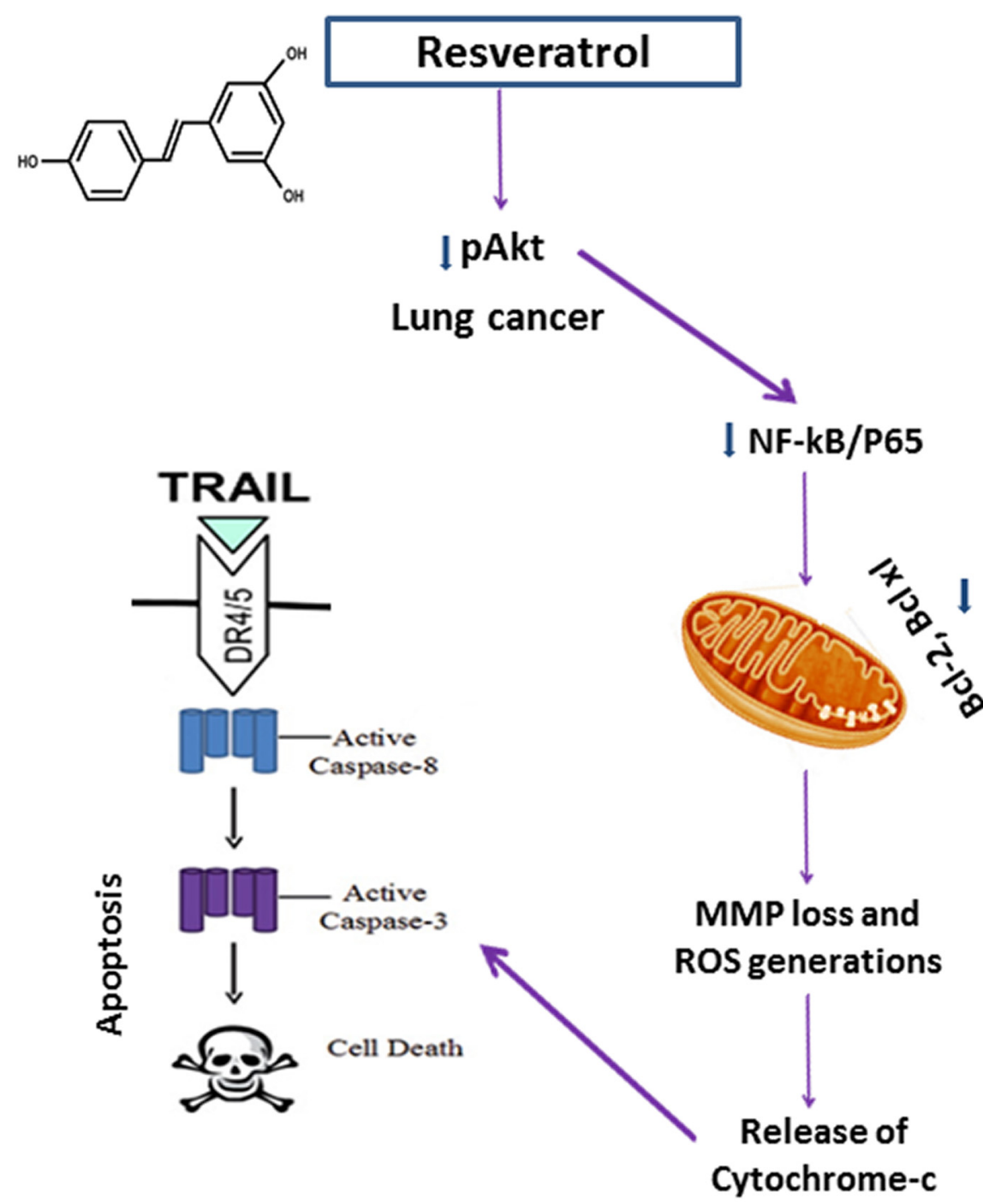

P

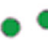

Fig. 9. The schematic diagram shows resveratrol induced TRAIL sensitization.

increase cell death, whereas a combined treatment enhanced apoptosis in a dose-dependent manner. This was shown by the activation of cleaved caspase- 8 and cleaved caspase- 3 in A549 and HCC-15 cells that were treated with both resveratrol and TRAIL. Again, Annexin V staining confirmed lower viable cells and finally in DAPI stinging fragmented nucleus was appeared in combined treatment (Figs. 1 and 2); therefore demonstrating that TRAIL resistance in lung cancer cells can be attenuated by a combined treatment. We then investigated the molecular mechanism underlying this apoptotic pathway. Previous reports have suggested that resveratrol has the capability to induce autophagy and might also play a role in enhancing apoptosis [54-56]. However, our western blot results revealed that treatment with different concentrations of resveratrol increased LC3-II accumulation and decreased p62 expression levels in A549 cells, thus confirming the activation of complete autophagy flux by lysosomal degradation (Fig. 3). Furthermore, to demonstrate the role of autophagy in resveratrol induced TRAIL-mediated apoptosis, we used chloroquine, a pharmacological autophagy inhibitor. Our result demonstrated that pretreatment with chloroquine did not rescue the cells undergoing apoptosis, suggesting that the apoptotic pathway was independent of autophagy flux (Fig. 4). To investigate the specific mechanism involved in resveratrol induced TRAIL-mediated apoptosis, we analyzed p53 and PUMA, both of which have been previously shown to have a potential role in apoptosis [48, 57-59]. Our findings demonstrate that resveratrol enhanced p53 acetylation, p53, and PUMA expression in a dose-dependent manner and was triggered by the combined treatment of resveratrol and TRAIL. To confirm the exact contribution of p53 during apoptosis, we used pifithrin- $\alpha$, p53 siRNA and p53 knockout cell line. Although knockdown of the upregulated expression of acetylated p53, p53, and PUMA. However in case of cell viability, the rescue of cells undergo apoptosis did not appear. Furthermore, cleaved caspase- 8 and caspase-3 remained unchanged in the co-treated groups (Figs. 5, 6). Overall, these results demonstrated that resveratrol-induced TRAILmediated apoptosis is independent of p53.

Additionally, NF- $\mathrm{KB}$ (p65) signaling may contribute to cellular proliferation, suppression of apoptosis, angiogenesis, and metastasis. The suppression of NF-kB (p65) has been shown to be an effective therapeutic in cancer treatments [60]. However, NF-kB (p65) has also been shown to contribute to TRAIL resistance [13]. NF-кB (p65) regulates $\mathrm{Bcl}-2$ and $\mathrm{Bcl}-\mathrm{xl}$, both of which localize to the mitochondrial outer membrane where they play a significant role in promoting cell survival and inhibiting the actions of Bax and Bak, which are known to promote permeabilization and the release of cytochrome $c$ for the initiation of apoptosis [28, 29, 61, 62]. Our data suggest that resveratrol 
treatment suppress the expression of phosphorylated Akt, which is involved in cell survival, thus resulting in the suppression of NF- $\mathrm{kB}$ (p65). PI3K/Akt inhibitor LY294002 combined with resveratrol and TRAIL significantly enhance the cells undergo apoptosis and suppression of NF- $\kappa B$ (p65) was also prominent. To confirm the relationship between p53 and NF-kB(p65), we used p53 $3^{+/+}$and p53 ${ }^{-/-}$HCT 116 cells and transfected them with a p53 siRNA. In both cases, NF-кB(p65) had no effect on p53 expression. The downregulation of Bcl-2 and Bcl-xl via resveratrol treatment also supported its role in an anti-cancer mechanism, especially since Bax remained unchanged (Fig. 7). Furthermore, the aggregation of JC monomers was an effective indicator for the MMP. The loss of MMP was due to the collapse of cell integrity during the initiation of apoptosis. Our data showed that the loss of MMP was highest in the resveratrol and TRAIL co-treated group, and ROS aggregations were found which lead to the release of cytochrome $c$. The translocation of cytochrome $c$ was observed from the fragile mitochondria into the cytoplasm in the treated group, whereas no changes in Bax localization were observed (Fig. 8). Overall, these studies conclude that resveratrol could attenuate TRAIL resistance in TRAIL-resistant cancer cells as well as simultaneously enhance TRAIL-mediated apoptosis via targeting the NF-kB (p65) signaling pathway. Finally, resveratrol potentiates TRAIL-based cancer treatment more effective and it could be the eminent therapeutic strategy in the lung cancer treatment regimen.

\section{Acknowledgments}

This study was supported by a grant from the National Research Foundation of Korea (NRF), funded by the Korean government (2016R1A2B2009293).

\section{Conflict of interest}

The authors declare no conflict of interest.

\section{References}

[1] A.B. Ryerson, C.R. Eheman, S.F. Altekruse, J.W. Ward, A. Jemal, R.L. Sherman, S.J. Henley, D. Holtzman, A. Lake, A.M. Noone, R.N. Anderson, J. Ma, K.N. Ly, K.A. Cronin, L. Penberthy, B.A. Kohler, Annual report to the nation on the status of cancer, 1975-2012, featuring the increasing incidence of liver cancer, Cancer 122 (9) (2016) 1312-1337.

[2] S. Schelhaas, A. Held, L. Wachsmuth, S. Hermann, D.J. Honess, K. Heinzmann, D.M. Smith, J.R. Griffiths, C. Faber, A.H. Jacobs, Gemcitabine mechanism of action confounds early assessment of treatment response by $3^{\prime}$-deoxy-3'-[18F] fluorothymidine in preclinical models of lung Cancer, Cancer Res. 76 (24) (2016) 7096-7105.

[3] K. Uchibori, N. Inase, M. Araki, M. Kamada, S. Sato, Y. Okuno, N. Fujita, R. Katayama, Brigatinib combined with anti-EGFR antibody overcomes osimertinib resistance in EGFR-mutated non-small-cell lung cancer, Nat. Commun. 8 (2017) 14768.

[4] M. Rasheduzzaman, S.Y. Park, Antihypertensive drug-candesartan attenuates TRAIL resistance in human lung cancer via AMPK-mediated inhibition of autophagy flux, Exp. Cell Res. 368 (1) (2018) 126-135.

[5] D.W. Stuckey, K. Shah, TRAIL on trial: preclinical advances in cancer therapy, Trends Mol. Med. 19 (11) (2013) 685-694.

[6] S. Wang, TRAIL: a sword for killing tumors, Curr. Med. Chem. 17 (29) (2010) 3309-3317.

[7] K. Kandasamy, S.M. Srinivasula, E.S. Alnemri, C.B. Thompson, S.J. Korsmeyer, J.L. Bryant, R.K. Srivastava, Involvement of proapoptotic molecules Bax and Bak in tumor necrosis factor-related apoptosis-inducing ligand (TRAIL)-induced mitochondrial disruption and apoptosis: differential regulation of cytochrome $c$ and Smac/DIABLO release, Cancer Res. 63 (7) (2003) 1712-1721.

[8] L. Zhang, B. Fang, Mechanisms of resistance to TRAIL-induced apoptosis in cancer, Cancer Gene Ther. 12 (3) (2005) 228-237.

[9] L. O'Leary, A.M. van der Sloot, C.R. Reis, S. Deegan, A.E. Ryan, S.P. Dhami, L.S. Murillo, R.H. Cool, P. Correa de Sampaio, K. Thompson, G. Murphy, W.J. Quax, L. Serrano, A. Samali, E. Szegezdi, Decoy receptors block TRAIL sensitivity at a supracellular level: the role of stromal cells in controlling tumour TRAIL sensitivity, Oncogene 35 (10) (2016) 1261-1270.

[10] T. Dan'ura, A. Kawai, Y. Morimoto, N. Naito, A. Yoshida, H. Inoue, Apoptosis and expression of its regulatory proteins in soft tissue sarcomas, Cancer Lett. 178 (2) (2002) 167-174.

[11] S. Hinz, A. Trauzold, L. Boenicke, C. Sandberg, S. Beckmann, E. Bayer, H. Walczak,
H. Kalthoff, H. Ungefroren, Bcl-XL protects pancreatic adenocarcinoma cells against CD95- and TRAIL-receptor-mediated apoptosis, Oncogene 19 (48) (2000) $5477-5486$.

[12] A. Trauzold, H. Wermann, A. Arlt, S. Schutze, H. Schafer, S. Oestern, C. Roder, H. Ungefroren, E. Lampe, M. Heinrich, H. Walczak, H. Kalthoff, CD95 and TRAIL receptor-mediated activation of protein kinase C and NF-kappaB contributes to apoptosis resistance in ductal pancreatic adenocarcinoma cells, Oncogene 20 (31) (2001) 4258-4269.

[13] D. Bernard, B. Quatannens, B. Vandenbunder, C. Abbadie, Rel/NF-kappaB transcription factors protect against tumor necrosis factor (TNF)-related apoptosis-inducing ligand (TRAIL)-induced apoptosis by up-regulating the TRAIL decoy receptor DcR1, J. Biol. Chem. 276 (29) (2001) 27322-27328.

[14] J.H. Moon, S.K. Eo, J.H. Lee, S.Y. Park, Quercetin-induced autophagy flux enhances TRAIL-mediated tumor cell death, Oncol. Rep. 34 (1) (2015) 375-381.

[15] U.M. Nazim, R. Md, Y.J. Lee, D.W. Seol, S.Y. Park, Enhancement of TRAIL-induced apoptosis by 5 -fluorouracil requires activating Bax and p53 pathways in TRAILresistant lung cancers, Oncotarget 8 (11) (2017) 18095-18105.

[16] M. Rasheduzzaman, J.H. Moon, J.H. Lee, U.M. Nazim, S.Y. Park, Telmisartan generates ROS-dependent upregulation of death receptor 5 to sensitize TRAIL in lung cancer via inhibition of autophagy flux, Int. J. Biochem. Cell Biol. 102 (2018) 20-30.

[17] R.A. Lockshin, Z. Zakeri, Apoptosis, autophagy, and more, Int. J. Biochem. Cell Biol. 36 (12) (2004) 2405-2419.

[18] M.C. Maiuri, E. Zalckvar, A. Kimchi, G. Kroemer, Self-eating and self-killing: crosstalk between autophagy and apoptosis, Nat. Rev. Mol. Cell Biol. 8 (9) (2007) 741-752.

[19] V.A. Soldatenkov, M. Smulson, Poly(ADP-ribose) polymerase in DNA damage-response pathway: implications for radiation oncology, Int. J. Cancer 90 (2) (2000) $59-67$.

[20] H. Okada, T.W. Mak, Pathways of apoptotic and non-apoptotic death in tumour cells, Nat. Rev. Cancer 4 (8) (2004) 592-603.

[21] A. Philchenkov, Caspases: potential targets for regulating cell death, J. Cell. Mol. Med. 8 (4) (2004) 432-444.

[22] M. Athar, C.A. Elmets, L. Kopelovich, Pharmacological activation of p53 in cancer cells, Curr. Pharm. Des. 17 (6) (2011) 631-639.

[23] M. Fischer, Census and evaluation of p53 target genes, Oncogene 36 (28) (2017) 3943-3956.

[24] S.A. Dyshlovoy, R. Madanchi, J. Hauschild, K. Otte, W.H. Alsdorf, U. Schumacher, V.I. Kalinin, A.S. Silchenko, S.A. Avilov, F. Honecker, V.A. Stonik, C. Bokemeyer, G. von Amsberg, The marine triterpene glycoside frondoside A induces p53-independent apoptosis and inhibits autophagy in urothelial carcinoma cells, BMC Cancer 17 (1) (2017) 93.

[25] Y. Nishida, A. Maeda, M.J. Kim, L. Cao, Y. Kubota, J. Ishizawa, A. AlRawi, Y. Kato, A. Iwama, M. Fujisawa, K. Matsue, M. Weetall, M. Dumble, M. Andreeff, T.W. Davis, A. Branstrom, S. Kimura, K. Kojima, The novel BMI-1 inhibitor PTC596 downregulates MCL-1 and induces p53-independent mitochondrial apoptosis in acute myeloid leukemia progenitor cells, Blood Cancer J. 7 (2) (2017) e527.

[26] B.B. Aggarwal, Nuclear factor-kappaB: the enemy within, Cancer Cell 6 (3) (2004) 203-208.

[27] A.C. Bharti, B.B. Aggarwal, Chemopreventive agents induce suppression of nuclear factor-kappaB leading to chemosensitization, Ann. N. Y. Acad. Sci. 973 (2002) 392-395.

[28] M. Zamora, C. Merono, O. Vinas, T. Mampel, Recruitment of NF-kappaB into mitochondria is involved in adenine nucleotide translocase 1 (ANT1)-induced apoptosis, J. Biol. Chem. 279 (37) (2004) 38415-38423.

[29] M. Chen, X. Wang, D. Zha, F. Cai, W. Zhang, Y. He, Q. Huang, H. Zhuang, Z.C. Hua, Apigenin potentiates TRAIL therapy of non-small cell lung cancer via upregulating DR4/DR5 expression in a p53-dependent manner, Sci. Rep. 6 (2016) 35468.

[30] O.N. Ozes, L.D. Mayo, J.A. Gustin, S.R. Pfeffer, L.M. Pfeffer, D.B. Donner, NFkappaB activation by tumour necrosis factor requires the Akt serine-threonine kinase, Nature 401 (6748) (1999) 82-85.

[31] G. Zhang, X. Ye, D. Ji, H. Zhang, F. Sun, C. Shang, Y. Zhang, E. Wu, F. Wang, F. Wu, H. Tian, X. Liu, L. Chen, K. Liu, Y. Wang, H. Liu, W. Zhang, Y. Guan, Q. Wang, $\mathrm{X}$. Zhao, X. Wan, Inhibition of lung tumor growth by targeting EGFR/VEGFR-Akt/ NF-kappaB pathways with novel theanine derivatives, Oncotarget 5 (18) (2014) 8528-8543.

[32] P. Jiang, N. Mizushima, Autophagy and human diseases, Cell Res. 24 (1) (2014) 69-79.

[33] R. Mathew, V. Karantza-Wadsworth, E. White, Role of autophagy in cancer, Nat. Rev. Cancer 7 (12) (2007) 961-967.

[34] N. Mizushima, Autophagy: process and function, Genes Dev. 21 (22) (2007) 2861-2873.

[35] D.J. Klionsky, H. Abeliovich, P. Agostinis, D.K. Agrawal, G. Aliev, D.S. Askew, M. Baba, E.H. Baehrecke, B.A. Bahr, A. Ballabio, B.A. Bamber, D.C. Bassham, E. Bergamini, X. Bi, M. Biard-Piechaczyk, J.S. Blum, D.E. Bredesen, J.L. Brodsky, J.H. Brumell, U.T. Brunk, W. Bursch, N. Camougrand, E. Cebollero, F. Cecconi, Y. Chen, L.S. Chin, A. Choi, C.T. Chu, J. Chung, P.G. Clarke, R.S. Clark, S.G. Clarke, C. Clave, J.L. Cleveland, P. Codogno, M.I. Colombo, A. Coto-Montes, J.M. Cregg, A.M. Cuervo, J. Debnath, F. Demarchi, P.B. Dennis, P.A. Dennis, V. Deretic, R.J. Devenish, F. Di Sano, J.F. Dice, M. Difiglia, S. Dinesh-Kumar, C.W. Distelhorst, M. Djavaheri-Mergny, F.C. Dorsey, W. Droge, M. Dron, W.A. Dunn Jr., M. Duszenko, N.T. Eissa, Z. Elazar, A. Esclatine, E.L. Eskelinen, L. Fesus, K.D. Finley, J.M. Fuentes, J. Fueyo, K. Fujisaki, B. Galliot, F.B. Gao, D.A. Gewirtz, S.B. Gibson, A. Gohla, A.L. Goldberg, R. Gonzalez, C. Gonzalez-Estevez, S. Gorski, R.A. Gottlieb, D. Haussinger, Y.W. He, K. Heidenreich, J.A. Hill, M. Hoyer-Hansen, X. Hu, W.P. Huang, A. Iwasaki, M. Jaattela, W.T. Jackson, X. Jiang, S. Jin, T. Johansen, 
J.U. Jung, M. Kadowaki, C. Kang, A. Kelekar, D.H. Kessel, J.A. Kiel, H.P. Kim, A. Kimchi, T.J. Kinsella, K. Kiselyov, K. Kitamoto, E. Knecht, M. Komatsu, E. Kominami, S. Kondo, A.L. Kovacs, G. Kroemer, C.Y. Kuan, R. Kumar, M. Kundu, J. Landry, M. Laporte, W. Le, H.Y. Lei, M.J. Lenardo, B. Levine, A. Lieberman, K.L. Lim, F.C. Lin, W. Liou, L.F. Liu, G. Lopez-Berestein, C. Lopez-Otin, B. Lu, K.F. Macleod, W. Malorni, W. Martinet, K. Matsuoka, J. Mautner, A.J. Meijer, A. Melendez, P. Michels, G. Miotto, W.P. Mistiaen, N. Mizushima, B. Mograbi, I. Monastyrska, M.N. Moore, P.I. Moreira, Y. Moriyasu, T. Motyl, C. Munz, L.O. Murphy, N.I. Naqvi, T.P. Neufeld, I. Nishino, R.A. Nixon, T. Noda, B. Nurnberg, M. Ogawa, N.L. Oleinick, L.J. Olsen, B. Ozpolat, S. Paglin, G.E. Palmer, I. Papassideri, M. Parkes, D.H. Perlmutter, G. Perry, M. Piacentini, R. Pinkas Kramarski, M. Prescott, T. Proikas-Cezanne, N. Raben, A. Rami, F. Reggiori, B. Rohrer, D.C. Rubinsztein, K.M. Ryan, J. Sadoshima, H. Sakagami, Y. Sakai, M. Sandri, C. Sasakawa, M. Sass, C. Schneider, P.O. Seglen, O. Seleverstov, J. Settleman, J.J. Shacka, I.M. Shapiro, A. Sibirny, E.C. Silva-Zacarin, H.U. Simon, C. Simone, A. Simonsen, M.A. Smith, K. Spanel-Borowski, V. Srinivas, M. Steeves, H. Stenmark, P.E. Stromhaug, C.S. Subauste, S. Sugimoto, D. Sulzer, T. Suzuki, M.S. Swanson, I. Tabas, F. Takeshita, N.J. Talbot, Z. Talloczy, K. Tanaka, K. Tanaka, I. Tanida, G.S. Taylor, J.P. Taylor, A. Terman, G. Tettamanti, C.B. Thompson, M. Thumm, A.M. Tolkovsky, S.A. Tooze, R. Truant, L.V. Tumanovska, Y. Uchiyama, T. Ueno, N.L. Uzcategui, I. van der Klei, E.C. Vaquero, T. Vellai, M.W. Vogel, H.G. Wang, P. Webster, J.W. Wiley, Z. Xi, G. Xiao, J. Yahalom, J.M. Yang, G. Yap, X.M. Yin, T. Yoshimori, L. Yu, Z. Yue, M. Yuzaki, O. Zabirnyk, X. Zheng, X. Zhu, R.L. Deter, Guidelines for the use and interpretation of assays for monitoring autophagy in higher eukaryotes, Autophagy 4 (2) (2008) 151-175.

[36] Y. Kabeya, N. Mizushima, T. Ueno, A. Yamamoto, T. Kirisako, T. Noda, E. Kominami, Y. Ohsumi, T. Yoshimori, LC3, a mammalian homologue of yeast Apg8p, is localized in autophagosome membranes after processing, EMBO J. 19 (21) (2000) 5720-5728.

[37] I. Tanida, N. Minematsu-Ikeguchi, T. Ueno, E. Kominami, Lysosomal turnover, but not a cellular level, of endogenous LC3 is a marker for autophagy, Autophagy 1 (2) (2005) 84-91.

[38] T.E. Rusten, H. Stenmark, p62, an autophagy hero or culprit? Nat. Cell Biol. 12 (3) (2010) 207-209.

[39] A.D. Kim, K.A. Kang, H.S. Kim, D.H. Kim, Y.H. Choi, S.J. Lee, H.S. Kim, J.W. Hyun, A ginseng metabolite, compound $\mathrm{K}$, induces autophagy and apoptosis via generation of reactive oxygen species and activation of JNK in human colon cancer cells, Cell Death Dis. 4 (2013) e750.

[40] A. Kim, N.H. Yim, J.Y. Ma, Samsoeum, a traditional herbal medicine, elicits apoptotic and autophagic cell death by inhibiting Akt/mTOR and activating the JNK pathway in cancer cells, BMC Complement. Altern. Med. 13 (2013) 233.

[41] M. Jang, L. Cai, G.O. Udeani, K.V. Slowing, C.F. Thomas, C.W. Beecher, H.H. Fong, N.R. Farnsworth, A.D. Kinghorn, R.G. Mehta, R.C. Moon, J.M. Pezzuto, Cancer chemopreventive activity of resveratrol, a natural product derived from grapes, Science 275 (5297) (1997) 218-220.

[42] L.G. Carter, J.A. D'Orazio, K.J. Pearson, Resveratrol and cancer: focus on in vivo evidence, Endocr. Relat. Cancer 21 (3) (2014) R209-R225.

[43] K.P.L. Bhat, J.W. Kosmeder II, J.M. Pezzuto, Biological effects of resveratrol, Antioxid. Redox Signal. 3 (6) (2001) 1041-1064.

[44] P. Kopp, Resveratrol, a phytoestrogen found in red wine. A possible explanation for the conundrum of the 'French paradox'? Eur. J. Endocrinol. 138 (6) (1998) 619-620.

[45] D. Vergara, A. Gaballo, A. Signorile, A. Ferretta, P. Tanzarella, C. Pacelli, M. Di Paola, T. Cocco, M. Maffia, Resveratrol modulation of protein expression in parkinmutant human skin fibroblasts: a proteomic approach, Oxidative Med. Cell. Longev. 2017 (2017) 2198243.

[46] C. Wright, A.K. Iyer, J.S. Yakisich, N. Azad, Anti-tumorigenic effects of resveratrol in lung cancer cells through modulation of c-FLIP, Curr. Cancer Drug Targets 17 (7) (2017) 669-680.

[47] Y. Bai, Q.Q. Mao, J. Qin, X.Y. Zheng, Y.B. Wang, K. Yang, H.F. Shen, L.P. Xie, Resveratrol induces apoptosis and cell cycle arrest of human T24 bladder cancer cells in vitro and inhibits tumor growth in vivo, Cancer Sci. 101 (2) (2010) 488-493.

[48] X. Wang, D. Wang, Y. Zhao, Effect and mechanism of resveratrol on the apoptosis of lung adenocarcinoma cell line A549, Cell Biochem. Biophys. 73 (2) (2015) 527-531.

[49] S. Ganapathy, Q. Chen, K.P. Singh, S. Shankar, R.K. Srivastava, Resveratrol enhances antitumor activity of TRAIL in prostate cancer xenografts through activation of FOXO transcription factor, PLoS One 5 (12) (2010) e15627.

[50] J.H. Ko, G. Sethi, J.Y. Um, M.K. Shanmugam, F. Arfuso, A.P. Kumar, A. Bishayee, K.S. Ahn, The role of resveratrol in cancer therapy, Int. J. Mol. Sci. 18 (12) (2017).

[51] B.B. Aggarwal, A. Bhardwaj, R.S. Aggarwal, N.P. Seeram, S. Shishodia, Y. Takada, Role of resveratrol in prevention and therapy of cancer: preclinical and clinical studies, Anticancer Res. 24 (5a) (2004) 2783-2840.

[52] X. Dai, J. Zhang, F. Arfuso, A. Chinnathambi, M.E. Zayed, S.A. Alharbi, A.P. Kumar, K.S. Ahn, G. Sethi, Targeting TNF-related apoptosis-inducing ligand (TRAIL) receptor by natural products as a potential therapeutic approach for cancer therapy, Exp. Biol. Med. (Maywood) 240 (6) (2015) 760-773.

[53] A. Eggert, M.A. Grotzer, T.J. Zuzak, B.R. Wiewrodt, R. Ho, N. Ikegaki, G.M. Brodeur, Resistance to tumor necrosis factor-related apoptosis-inducing ligand (TRAIL)-induced apoptosis in neuroblastoma cells correlates with a loss of caspase8 expression, Cancer Res. 61 (4) (2001) 1314-1319.

[54] C.H. Chang, C.Y. Lee, C.C. Lu, F.J. Tsai, Y.M. Hsu, J.W. Tsao, Y.N. Juan, H.Y. Chiu, J.S. Yang, C.C. Wang, Resveratrol-induced autophagy and apoptosis in cisplatinresistant human oral cancer CAR cells: a key role of AMPK and Akt/mTOR signaling, Int. J. Oncol. 50 (3) (2017) 873-882.

[55] S. Hu, X. Li, R. Xu, L. Ye, H. Kong, X. Zeng, H. Wang, W. Xie, The synergistic effect of resveratrol in combination with cisplatin on apoptosis via modulating autophagy in A549 cells, Acta Biochim. Biophys. Sin. 48 (6) (2016) 528-535.

[56] D. Park, H. Jeong, M.N. Lee, A. Koh, O. Kwon, Y.R. Yang, J. Noh, P.G. Suh, H. Park, S.H. Ryu, Resveratrol induces autophagy by directly inhibiting mTOR through ATP competition, Sci. Rep. 6 (2016) 21772.

[57] Y.A. Kim, W.H. Lee, T.H. Choi, S.H. Rhee, K.Y. Park, Y.H. Choi, Involvement of p21WAF1/CIP1, pRB, Bax and NF-kappaB in induction of growth arrest and apoptosis by resveratrol in human lung carcinoma A549 cells, Int. J. Oncol. 23 (4) (2003) 1143-1149.

[58] L. Yuan, Y. Zhang, J. Xia, B. Liu, Q. Zhang, J. Liu, L. Luo, Z. Peng, Z. Song, R. Zhu, Resveratrol induces cell cycle arrest via a p53-independent pathway in A549 cells, Mol. Med. Rep. 11 (4) (2015) 2459-2464.

[59] D.C. Ferraz da Costa, F.A. Casanova, J. Quarti, M.S. Malheiros, D. Sanches, P.S. Dos Santos, E. Fialho, J.L. Silva, Transient transfection of a wild-type p53 gene triggers resveratrol-induced apoptosis in cancer cells, PLoS One 7 (11) (2012) e48746.

[60] Y.T. Yang, C.J. Weng, C.T. Ho, G.C. Yen, Resveratrol analog-3,5,4'-trimethoxytrans-stilbene inhibits invasion of human lung adenocarcinoma cells by suppressing the MAPK pathway and decreasing matrix metalloproteinase-2 expression, Mol. Nutr. Food Res. 53 (3) (2009) 407-416.

[61] D. Deeb, X. Gao, Y. Liu, Y. Zhang, J. Shaw, F.A. Valeriote, S.C. Gautam, The inhibition of cell proliferation and induction of apoptosis in pancreatic ductal adenocarcinoma cells by verrucarin A, a macrocyclic trichothecene, is associated with the inhibition of Akt/NF-small ka, CyrillicB/mTOR prosurvival signaling, Int. J. Oncol. 49 (3) (2016) 1139-1147.

[62] S.D. Catz, J.L. Johnson, Transcriptional regulation of bcl-2 by nuclear factor kappa $\mathrm{B}$ and its significance in prostate cancer, Oncogene 20 (50) (2001) 7342-7351. 